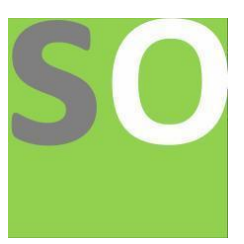

Article title: Hypothesis of Potential Evolution of SARS-CoV-2 through Hybridization of SARS-CoV-1 with Saccharomyces cerevisiae and Mycobacterium avium naturally inside an immunocompromised Pangolin

Authors: Shimaa Abdelgawad[1]

Affiliations: Pharmacognosy Department, Faculty of Pharmacy, Fayoum University, 63514, Egypt[1]

Orcid ids: 0000-0002-4160-1625[1]

Contact e-mail: smm13@fayoum.edu.eg

License information: This work has been published open access under Creative Commons Attribution License http://creativecommons.org/licenses/by/4.0/, which permits unrestricted use, distribution, and reproduction in any medium, provided the original work is properly cited. Conditions, terms of use and publishing policy can be found at https://www.scienceopen.com/.

Preprint statement: This article is a preprint and has not been peer-reviewed, under consideration and submitted to ScienceOpen Preprints for open peer review.

DOI: 10.14293/S2199-1006.1.SOR-.PPDO2ZU.v1

Preprint first posted online: 31 December 2020

Keywords: Evolution, SARS-CoV-2, Microbial interaction, SARS-CoV-1, Saccharomyces cerevisiae and Mycobacterium avium 


\title{
Hypothesis of Potential Evolution of SARS-CoV-2 through Hybridization of SARS-CoV-1 with Saccharomyces cerevisiae and Mycobacterium avium naturally inside an
} immunocompromised Pangolin

\author{
Shimaa M. Abdelgawad * \\ Pharmacognosy Department, Faculty of Pharmacy, Fayoum University, 63514, Egypt \\ Email: smm13@fayoum.edu.eg
}

\section{Abstract \\ Background}

Discovery of the origin of SARS-CoV-2 become an urgent international need due to the current health and economic implications. Recently, pangolins were reported to have a diminished immunity and vulnerable to several infections. By the end of 2019; recent studies reported the pangolin's infection with SARS like virus that showed a 99\% genetic homology with SARS-CoV-2. In 2020; a genetic mutation was reported in pangolins that increases their vulnerability to infection with flagellated bacteria such as Mycobacterium species. Moreover, the introduced food formula containing yeast at several zoos, considered as a source of opportunistic Saccharomyces infection in such immunocompromised pangolins.

\section{Methods}

The coexistence of multiple infections in an immunocompromised pangolin is the concept of SARS-CoV2 evolution hypothesis. The structures of the three proposed microorganisms; SARS-CoV-1, Saccharomyces cerevisiae and Mycobacterium avium as well as their glycobiology and host cell interactions were studied. The $\alpha$-mannoses and phosphates present in the spike protein of SARS-CoV-2 is supposed to be introduced through fermentation of the spike protein of SARS-CoV-1 by Saccharomyces cerevisiae while the PRRAR furin putative sequence as well as the LDPLSE motif are supposed to be introduced through microbial interaction with Mycobacterium avium strain 104. Moreover, the interaction 
with pangolin's cells resulted in the presence of the reserved O-glycosylation sites in the spike protein of SARS-CoV-2.

\section{Results and discussion}

SARS-CoV-2 was naturally developed in an immunocompromised pangolin through microbial interaction that resulted in a hybrid microorganism containing viral RNA encapsulated within a glycan shield (Spike glycoprotein) manipulated by both Saccharomyces cerevisiae and Mycobacterium avium.

The proposed origin of the novel virus; SARS-CoV-2, explained the abnormal clinical findings such as disseminated infection, blood clotting, hyperpigmentation in some cases and Kawasaki like syndrome in kids. Lactose intolerance is also suggested as a new genetic risk factor that increases the vulnerability to infection with SARS-CoV-2. Moreover, the likelihood biofilm formation by SARS-CoV-2 is discussed. Furthermore, this hypothesis discussed the potential evolution of MERS through microbial interaction between Mycobacterium tuberculosis and SARS-CoV-1 virus.

\section{Conclusions}

Trials using triple therapy treatment strategy consisting of Remdesivir, Aithromycin and fluorocytosine as well as a yeast-based vaccine are suggested.

Key words: Evolution, SARS-CoV-2, Microbial interaction, SARS-CoV-1, Saccharomyces cerevisiae and Mycobacterium avium 


\section{Background}

In December 2019, a cluster of pneumonia cases epidemiologically linked to the Huanan seafood market in Wuhan city (Hubei Province), China $[1,2]$ were reported. In early January, the etiological agent of the pneumonia cases was found to be a coronavirus that was subsequently named SARS-CoV-2 [3-5]. The first genomic sequence of SARS-CoV-2 was reported on January 10, 2020 [6]. A phylogenetic comparison of SARS-CoV-2 with other CoVs showed that bats were considered as the native host of SARSCoV-2 as the new virus is $96 \%$ identical to two SARS-like CoVs from bats called bat-SL-CoVZX45 and bat-SLCoVZX21 [7]. Researchers in Guangzhou, China, suggested that pangolins are the potential intermediate host of SARS-CoV-2 based on 99\% genetic homology in a CoV discovered in pangolins and SARS-CoV-2 [8].

Figuring out the original source of SARS-CoV-2 become an international demand because of the current health and economic implications. In outbreaks of zoonotic pathogens, identification of the infection source is crucial, as this may allow health authorities to separate human populations from the animal reservoirs posing the zoonotic risk $[9,10]$. Identification of the exact source of the virus is important to answer the outstanding evolutionary question about whether the virus was laboratory manipulated or naturally developed. Moreover, it is of a great benefit while developing a vaccine and/or treatment.

A well-known model for microbe-microbe interaction is the human microbiota where commensal microorganisms (bacteria, archaea, viruses, and microscopic eukaryotes) are engaged in a constant crosstalk together and with the host immune system and metabolism [11].

One of the recent studies discussed the evidence of recombination in coronaviruses implicating a pangolin origin of nCoV-2019 [12]. Another recent mathematical study found an evidence of recombination event at least 11 years ago in an ancestor of the SARS-CoV-2 involving the RBD and stated that SARSCoV-1 and SARS-CoV-2 share a similar genotype in RBD [13] that could show the fact of SARS-CoV-2 
is a recombination product of SARS- CoV-1. This proposed fact come in accordance with the hypothesis to be discussed in that article.

The yeast Saccharomyces cerevisiae has been used as cell factory for production of several biopharmaceuticals proteins such as insulin, human serum albumin, hepatitis vaccines and virus like particles used for vaccination against human papillomavirus [14]. The ability of yeast to change the structure of SARS virus has been previously described in a research that stated the high-yield expression of recombinant SARS coronavirus nucleocapsid protein in methylotrophic yeast Pichia pastoris [15]. More recent research illustrated the ability for re-construction and cloning of the viral genome RNA of SARSCoV-2 in one step using Saccharomyces cerevisiae [16].

Pangolins are unique placental mammals which have adapted to a highly specialized diet of ants and termites, and are of significance in the control of forest termite disaster [17]. Besides their ecological worth, pangolins are very necessary economic animals with the worth as drugs and food. Pangolin meat is cooked in lees (dead yeast and debris) and sold in China as a street food during the winter [18]. Additionally; the Chinese traditional medicine prescribes the pangolin scales for a variety of ailments such as excessive anxiety in children, women thought to be possessed by devils, malarial fever, and deafness [19]. Pangolins are traditionally used in Chinese medicine for promoting menstruation and lactation, reducing swelling and promoting discharge of pus in abscesses and boils and for rheumatism/arthritis [20]. Moreover, there are a lot of Chinese patents registered for treatment of different types of tuberculosis based on the pangolin scales as a medicine for treating lymphatic tuberculosis [21, 22], mammary glands tuberculosis [23-25], tuberculosis in bone and joint [26, 27], lung tuberculosis [28, 29].

Recently, captive breeding is an important way to protect pangolins from extinction due to illegal hunting and habitat destruction [17], but there are several technical barriers to successful captive breeding programs such as pangolin's high dependence on natural ecosystem and availability of suitable accommodation and artificial diet. The Taipei Zoo developed a food formula to improve the food intake 
and digestive disorders that contains a high amount ( $2 \mathrm{~g})$ of yeast powder [30]. Because of pangolin's poor adaptability to captive environment and a weak immune system, over 50 percent of captive pangolins died of hemorrhagic gastric ulcers and pneumonia [31]. Skin diseases and parasitic infection (ticks and mites) are also common in pangolins especially for those seized from illegal trade due to the mess and dirty transportation process $[17,32,33]$. These parasites probably cause pangolins to be anemic, wasting, immunocompromised and vulnerable to infectious disease, and even death [17].

The abuse of probiotic preparations containing Saccharomyces cerevisiae can cause a wide variety of clinical syndromes in humans including Pneumonia [34-36]. And as well, Yeast could be an opportunistic microorganism that could infect the immunocompromised pangolins causing diseases such as pneumonia.

On 24 October 2019, researchers from the Guangdong Wildlife Rescue Center of China first detected the existence of a SARS-CoV-like CoV from lung samples of two dead Malayan pangolins with a frothy liquid in their lungs and pulmonary fibrosis [37].

Another recent study in 2020 stated that a genetic mutation happened in pangolins results in convergent losses of TLR5 (Toll like receptors) that play an important role for the innate immune system. TLR5 encodes the major extracellular receptor for detection bacterial flagellin [38] and as a result this could increase the risk of pangolin infection with a flagellated bacteria such as Mycobacterium species.

In this hypothetical study, it is proposed that SARS-CoV-2 originated in an immunocompromised pangolin co-infected by SARS-CoV-1 like virus, Saccharomyces cerevisiae and Mycobacterium avium strain 104 through microbe-microbe interaction that led to generation of the novel virus; which is a virus containing both fungal and bacterial epitopes.

\section{Methods}

(i) Study of the spike glycoprotein of SARS-CoV-2 compared to SARS-CoV-1, (ii) Hypothesis of hybridization of SARS-CoV-1 with Saccharomyces cerevisiae and Mycobacterium avium, (iii) 
Comparative study for the diseases pattern caused by SARS-CoV-2, Saccharomyces cerevisiae and Mycobacterium avium

(i) Study of the spike glycoprotein of SARS-CoV-2:

Since COVID-19 outbreak in December 2019, scientists all over the world started to study the structure of the new virus comparing it to the previous human coronaviruses such as SARS, MERS and HKU1 CoVs [39-41]. Most studies tried to Figures out the structure of spike protein which is reported to bind to ACE 2 receptor [42, 43] as well as CD209L, a C-type lectin [41].

There are several unique features discovered in the structure of the spike (S) protein of SARS-CoV2 virus:

(1) Six RBD amino acids have been shown to be critical for binding to ACE2 receptors. In SARS-CoV1, they are Y442, L472, N479, D480, T487 and Y4911, which correspond to L455, F486, Q493, S494, N501 and Y505 in SARS-CoV-2 [44].

(2) The spike protein of SARS-CoV-2 has a functional polybasic (furin) cleavage site at the S1-S2 boundary (aa 677-687) through the insertion of 12 nucleotides that contains a contains a putative furin recognition motif (PRRARSV) [44, 45].

(3) $O$-glycosylation: SARS-CoV-2 S1 protein show conserved $O$-glycosylation $(O$-GalNAc and $O$ GlcNAc) at Ser673, Thr678, and Ser686 [44]. S1 protein was found to be $O$-GalNAcylated at Thr632, Thr673 and Thr678 and $O-\beta$-GlcNAcylated at Thr323, Thr632, Thr638, Ser686 [41].

(4) $N$-glycosylation: SARS-CoV-2 S proteins are extensively glycosylated viral fusion proteins, encoding $22 \mathrm{~N}$-glycosylation sites per trimeric spike [40] that showed a three apical conserved $\mathrm{N}$-glycosylation sites; (N 17, N 74 and N 657) that was not reported in SARS-CoV-1 [39]. The majority of $N$-glycan moieties in SARS-CoV-2 are simple mannose type (Man3Glc to Man5Glc) [40] (Fig. 1) while SARSCov-1 spike protein revealed the presence of more complex oligomannose-type glycans 
(Man5GlcNAc2 to Man9GlcNAc2) reveals that the majority of $N$-linked glycans are able to be processed (Fig. 1S) [39].

Another important issue to be noted about oligomannose-type glycans in SARS-CoV-2; is their ability to bind to C-type lectin (CD209L) through $\alpha$-mannose residue to mediate the endocytosis of pathogens indicating the alpha configuration of mannose sugar in glycoprotein of SARS CoV-2 in contrast with the beta mannose in SARS-CoV-1 [41].

(5) Phoshphorylation: SARS-CoV-2 S1 protein was examined and 36 positions of Ser/Thr residues were found to be phosphorylated on almost all domains of the protein. Some phosphorylation positions were neighbors to the conserved $O$ - and $N$-glycosylation sites on the 3D structure [41] .

(6) LxxIxE-like motif: a recent research detected the presence of LxxIxE-like motif (LDPLSE ) in S1subunit that could recruit the host protein phosphatase 2A (PP2A) [46] and this motif is conserved in SARS-CoV-2 and LIDLQE in S2 subunit which is conserved in S2 subunit of SARS-CoV-2, SARSCoV, SARS-like of bat from China and Kenya [46].

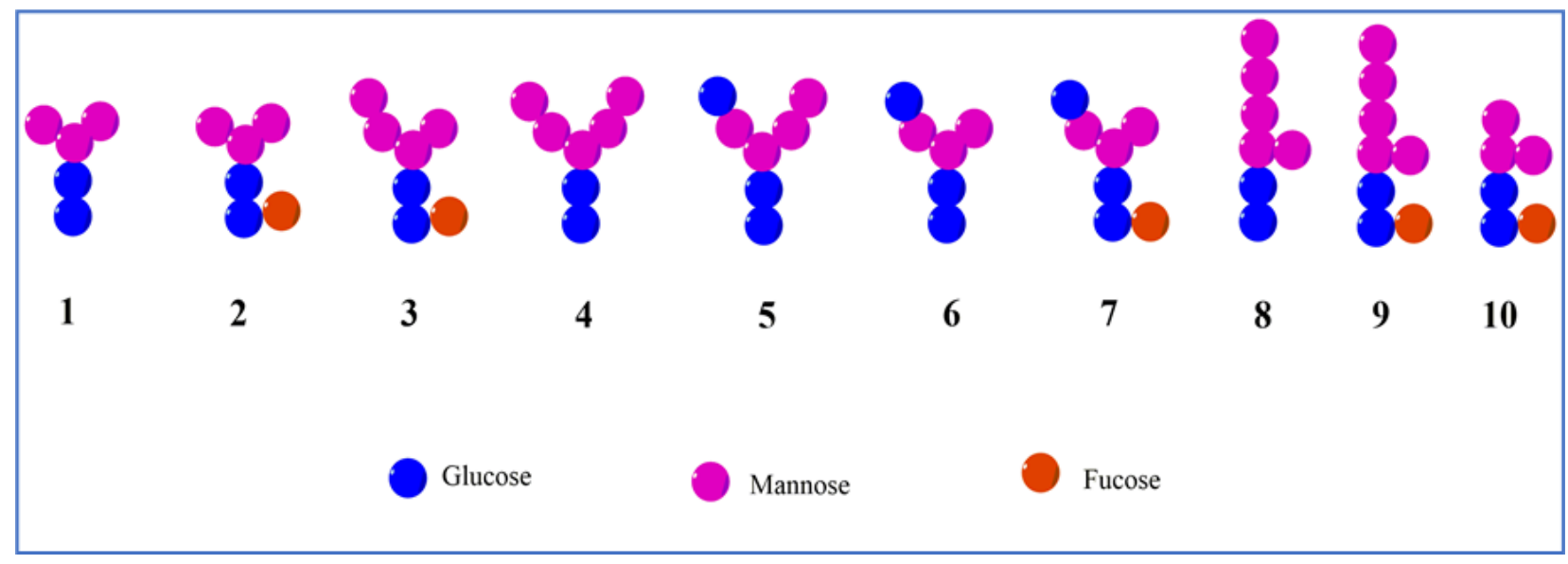

Fig. 1. Structure of S glycoprotein reported in SARS-CoV-2

(ii) Hypothesis of Hybridization of SARS-CoV-1 with Saccharomyces cerevisiae and Mycobacterium avium 


\section{A. Hypothesis statement (Fig. 2).}

"The base of this hypothesis depends on the assumption that the spike protein of the SARS-CoV-1 (assigned as CoV-A) virus is highly mannosylated (Man5GlcNAc2 to Man9GlcNAc2) glycoproteins. In a glucose deficient medium such as inside pangolin's macrophage cells, the mannose sugar in CoV-A glycans could be utilized by Saccharomyces cerevisiae for its energy production as well as mannosylation reactions. The microbial reaction started with endocytosis of $\mathrm{CoV}-\mathrm{A}$ inside yeast cells followed by phosphorylation of the spike glycoprotein of CoV-A (to stop endocytosis) and then fermentation of CoV-A mannosyl glycan. At this point, the virus is naked from most of its glycan shield (assigned as CoV-B) and in a trial to rebuild its shield, it enters the Golgi apparatus of S. cerevisiae and makes use from the yeast specific mannosylation reactions in its Golgi, acquiring some of the $\alpha$-mannose sugars and attaching it to its spike as a shield and then exocytosed from $S$. cerevisiae as a new $\mathrm{CoV}$ virus (assigned as $\mathrm{CoV}-\mathrm{C}$ ). $\mathrm{CoV}-\mathrm{C}$ passes through the Golgi of pangolin cells where it is trimmed of some of its mannoses and then its glycoprotein is humanized

(O-glycosylated) that led to emergence of another mutant of the virus (assigned as CoV-D). Last step in this interaction happens if a pangolin is co-infected by CoV-D and Mycobacterium avium strain 104. Both microbes have similar $\alpha$-mannose epitopes and negatively charged surface due to presence of phosphate, so, they could share together to form a biofilm. Inside that biofilm, HBHA (Heparin-binding hemagglutinin) or extracellular DNA of Mycobacterium avium could be attached to CoV-D spikes at the S1/S2 fusion site (proteoglycan like site) introducing PRRAR sequence that triggered the furin cleavage at that site.” 


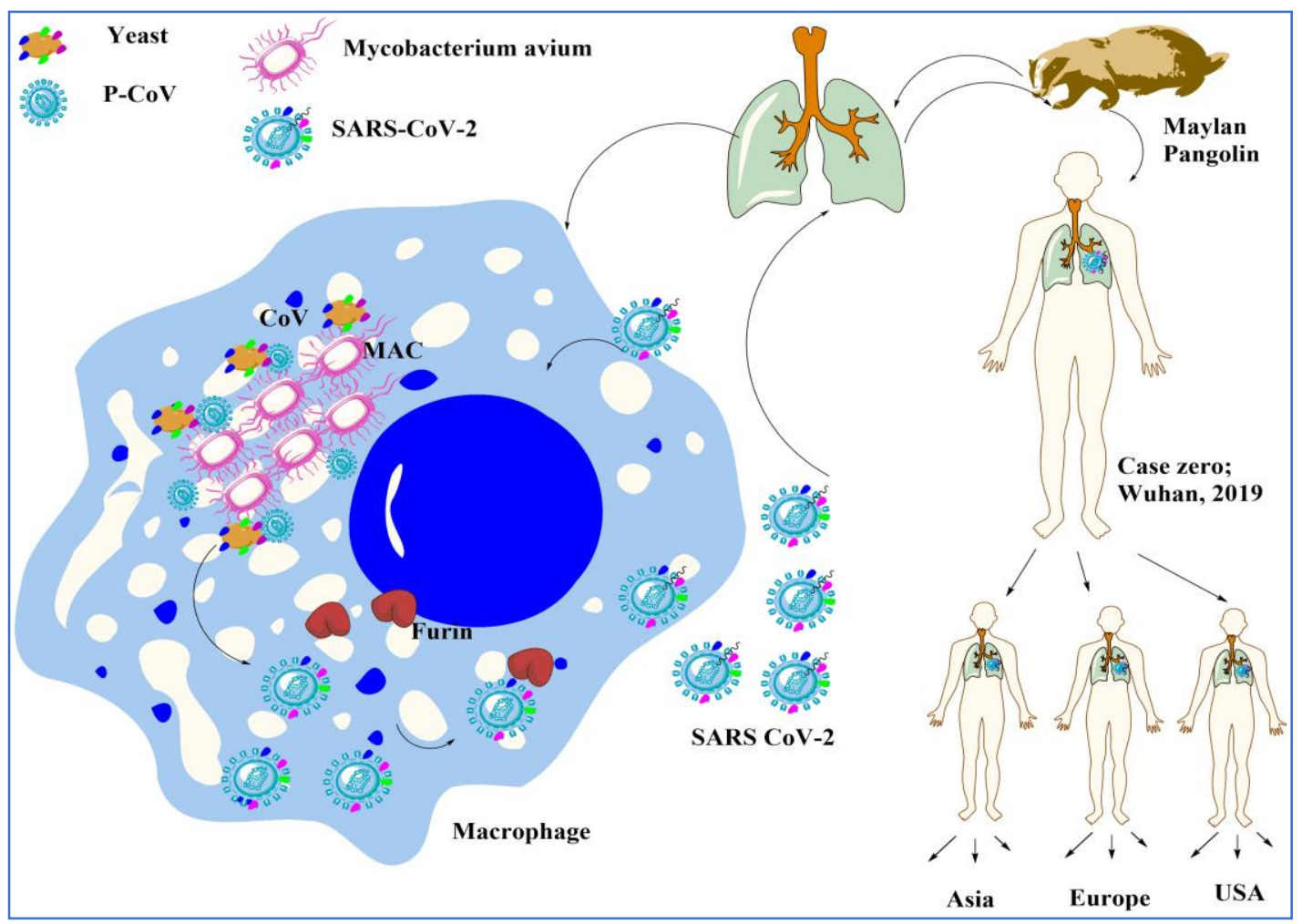

Fig. 2. Hypothesis of Hybridization of $\mathrm{CoV}$ with yeast (S. cerevisiae) and M. avium

\section{Hypothesis mechanism}

1- Endocytosis, fermentation, phosphorylation and $\alpha$-mannosylation of SARS-CoV-1 (CoV-A) Spike protein by Saccharomyces cerevisiae

Endocytosis, fermentation: The preferred carbon source for $S$. cerevisiae is glucose under both fermentative and non-fermentative conditions [47]; however, when the supply of glucose is exhausted and oxygen is present, the cells can utilize other present sugars such as fructose or mannose [48] or even it can use nonfermentable carbon sources, such as lactate [49]. Spike glycoproteins of CoV viruses are highly mannosylated proteins varies from Man5GlcNAc2 to Man9GlcNAc2 glycans. Mannose can be utilized for energy production in S. cerevisiae and for mannosylation reactions in the yeast cell, including those involved in $\mathrm{N}$-linked and $O$-linked glycosylation of yeast proteins and synthesis of the lipid anchor glycosylphosphatidylinositol $[48,50]$. So, the first step in microbial interaction is the endocytosis of $(\mathrm{CoV}$ A) by Saccharomyces cerevisiae as a sugar. 
Sugars endocytosis or uptake from the environment is controlled by a family of facilitative glucose transporters known as HXTs (hexose transporters) in Saccharomyces cerevisiae [51]. Once sugar get inside the cell, the concerted actions of glycolysis, citric acid cycle, and oxidative phosphorylation are used to generate a reservoir of adenonsine triphopshpate (ATP) [52]. In S. cerevisiae, utilization of mannose begins with its phosphorylation to mannose-6-phosphate (M6P) by hexokinase (Hxk1p or Hxk2p) or glucokinase (Glk1p). When yeast cells are grown on mannose as a carbon source, only HXK2 is highly expressed. M6P can either be converted to GDP-mannose to support mannosylation reactions in the cell or converted to fructose-6-phosphate (F6P) to fuel glycolysis (Fig. 2S) [53]. At this step, glycoprotein mannose sugar of CoV-A is fermented by Glk1p and HXK2 of S. cerevisiae leaving the virus naked from most of its glycan shield (assigned as CoV-B).

Phosphorylation: Glucose uptake/ATP energy balance in the cell of Saccharomyces cerevisiae is regulated by adenosine monophosphate (AMP) activated protein kinase called Snf1, that has been shown to phosphorylate and inhibit multiple members of a protein trafficking adaptor family, known as the $\alpha$ arrestins (Rod1, Rog3, and Csr2), which are responsible for the endocytosis. Phosphorylation of the $\alpha$ arrestins prevents $\alpha$-arrestin-mediated endocytosis of glucose and other carbohydrate transporters [52, 54]. Snf1 kinase could be the enzyme responsible for phosphorylation of Ser amino acids of the spike protein of SARS-CoV-2 which is phosphorylated parallel to $\alpha$-arrestins after endocytosis of high amount of the virus and production of high level of ATP, (Fig. 3). Snf1 phosphorylate at Ser exclusively (i.e., not Thr) [54]. Protein phosphorylation is an extremely important mechanism of cellular regulation in Saccharomyces cerevisiae that expresses over $110 \mathrm{Ser} / \mathrm{Thr}$ protein kinases [55] that could also take part in Ser/Thr phosphorylation of SARS-CoV-2 spike protein.

$N$-glycan synthesis ( $\alpha$-mannosylation) in the Golgi apparatus of yeast: in contrast to mammals, yeast $S$. cerevisiae does not trim the ER-derived $N$-glycan but extends it either a core-type structure that contains just a few extra residues and is found on the intracellular glycoproteins, such as carboxypeptidase Y [56] or to a mannan structure that consists of a long branched polymer of approximately 200 mannoses 
attached to proteins [57]. GDP-mannose is utilized as a mannose donor in mannosylation in the Golgi with the help of several enzymes such as Och1p, $(\alpha-1,6$-mannosyltransferase) that adds one mannose residue to both types of $N$-glycan $[57,58]$.

Coronaviruses have been previously reported to form virions by budding into the lumen of endoplasmic reticulum-Golgi intermediate compartments (ERGIC) [59-61] with the observations of hybrid- and complex-type glycans on virally derived material $[62,63]$.

In budding yeast Saccharomyces cerevisiae; Serine/threonine-linked glycans (O-glycans) of yeast species generally consist of $\alpha-1,2-$ and $\alpha-1,3-$ linked mannose residues [56]. Most of Ser/Thr sites at CoV-B are blocked through phosphorylation in the previous step, so $O$-glycosylation at these sites was not accomplished. $N$ - glycosylation of spike protein of CoV-B was performed in a way that mimic the core-type structure that contains just a few extra residues of $\alpha$-mannoses. In another words, S. cerevisiae considered CoV-B as its intracellular glycoproteins, such as carboxypeptidase $\mathrm{Y}$ and resulted in a new form of virus (assigned as CoV-C) (Fig. 3). CoV-C is now ready for exocytosis from the yeast cells to start a new modification pathway inside the mammalian or pangolin cells. 


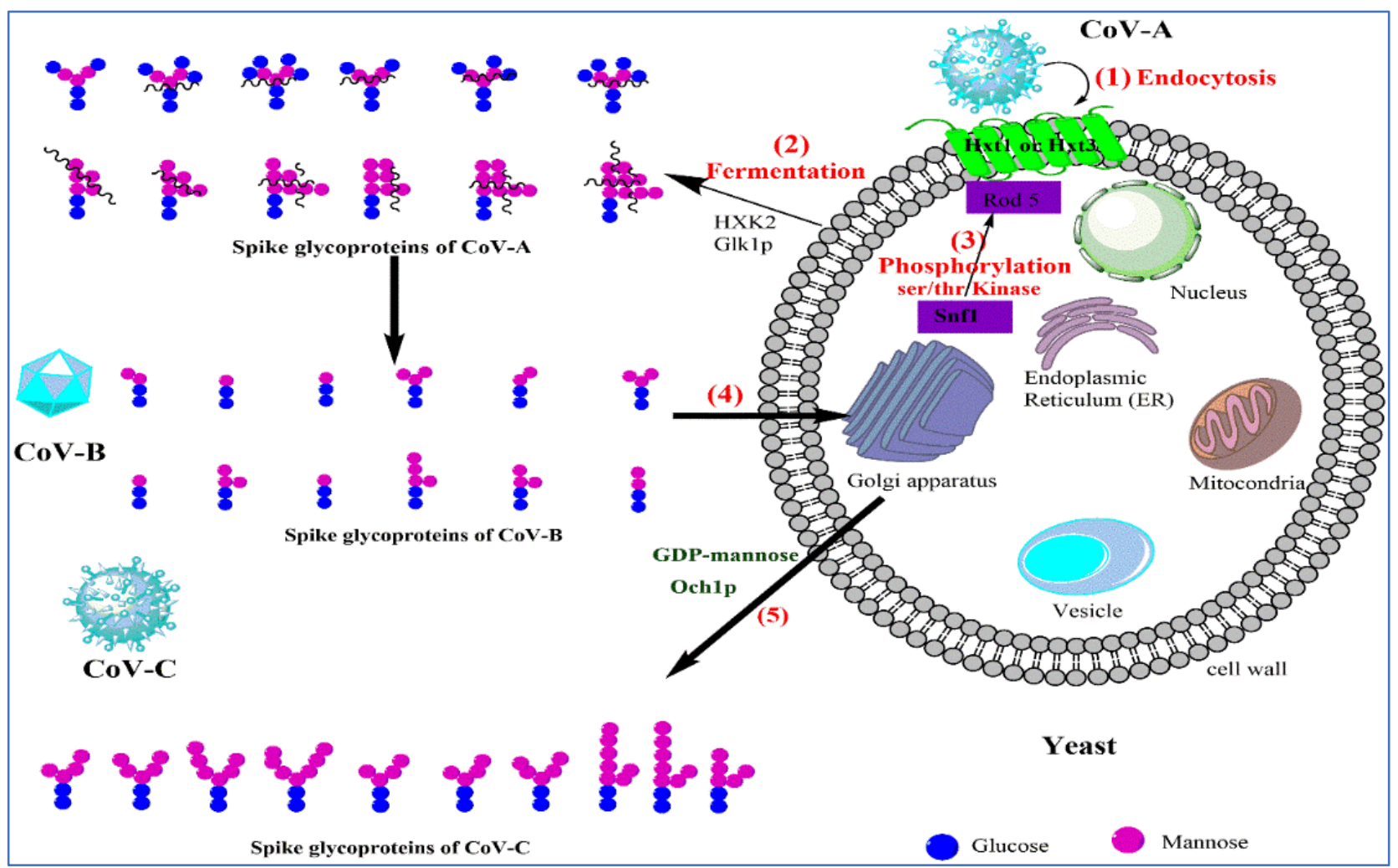

Fig. 3. Interaction of P-CoV (SARS-CoV-1) with Saccharomyces cerevisiae; endocytosis, fermentation,

\section{phosphorylation and $\alpha$-mannosylation}

Hxt: Hexose transporters, Hxk: hexokinase, Glk1p: glucokinase, Och1p, ( $\alpha-1,6$ mannosyltransferase).

\section{2- CoV spike $O$-glycosylation and $N$-glycoprotein humanization inside pangolin Golgi}

In mammalian cells, some mannose residues in the core form, Man8GlcNAc2, are trimmed during protein transport from the ER to the Golgi apparatus, in which several different sugars such as $N$ acetylglucosamine, galactose, sialic acid, and/or fucose are added to achieve complexity [64]. And so; $\mathrm{CoV}$ spike glycoprotein (CoV-C) when enters the Golgi of pangolin cells will be subjected to subsequent events such as trimming of one mannose and then protein humanization that was carried out by fucosylation and glucosylation. Moreover, $O$-glycosylation of Spike protein of CoV-C could proceed also in this stage adding ( $O$-GalNAc and $O$-GlcNAc) to $\mathrm{S}$ protein that was found to be $O$-GalNAcylated at 
Thr632, Thr673 and Thr678 and $O$ - $\beta$-GlcNAcylated at Thr323, Thr632, Thr638, Ser686 [44]. These consequent events resulted in a new form of the virus assigned as CoV-D, (Fig. 4).

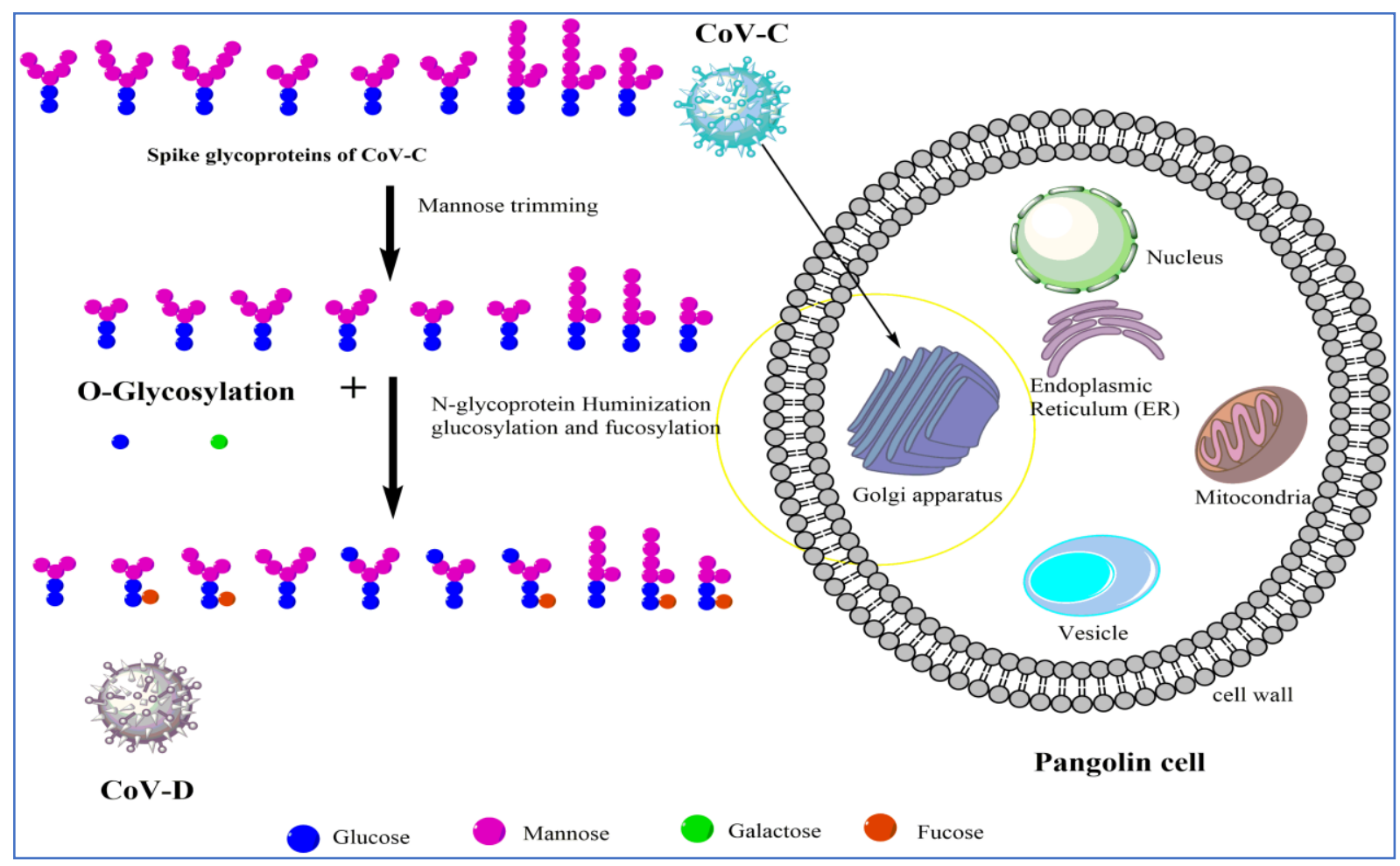

Fig. 4. CoV spike $O$-glycosylation and $N$-glycoprotein humanization by pangolin Golgi

\section{3- CoV-D hybridization with Mycobacterium avium}

Mycobacterium avium is an ubiquitous environmental bacteria encountered in natural and urban water sources as well as soil [65] and is considered as opportunistic pathogen of humans [66-69], domestic and wild animals [70], poultry and fish [71].

Mycobacterium avium has been shown to produce a biofilm or a biofilm-like structure [72]. In $M$. avium biofilm matrix is associated with three components; a glycopeptidolipid (GPL) present on the cell wall [69], extracellular DNA (eDNA) that has been found to be a major component of bacterial biofilms produced by Mycobacterium avium subsp. hominissuis [73]. And as well, heparin-binding hemagglutinin (HBHA) adhesin; a bacterial cell surface-associated protein is one of the biofilm components [74]. 


\section{Role of biofilm matrix of Mycobacterium avium in the interaction with CoV-D}

At first, the bacterial cells detect required environmental signals including nutrients concentrations (glucose, indole, polyamines), inorganic molecules (iron, phosphate), $\mathrm{pH}$, antimicrobials, temperature, oxygen concentration, osmolarity, and host derived signals (bile acids, hyrogen peroxide) [75-77]. Then the biofilm construction starts with reversible attachment of bacteria to a favorable surface according to the physicochemical and electrostatic interactions between the bacterial envelope itself and the substrate [7577]. According to the previous parameters, CoV-D could be considered as an excellent substrate to which M. avium can adhere through biofilm formation. It provides a good source of sugar and phosphorous and as well the structural similarity between the glycans of CoV-D (Fig. 4) and manno-glycans of M. avium [78] (Fig. 3S) allows CoV-D to share in the biofilm assembly by M. avium.

The interaction of CoV-D with Mycobacterium avium could be mediated through three steps during the biofilm formation:

\section{a) Introduction of a Proline residue at S1/S2 fusion site in CoV-D}

$\underline{\text { Two scenarios are suggested for such interaction: }}$

1- First scenario is suggested to be through interaction with Heparin-binding hemagglutinin (HBHA) protein:

HBHA is expressed at the surface of a variety of mycobacterial species and promotes binding of the bacteria to each other and to host epithelial cells. It is the responsible adhesin for extra-pulmonary dissemination [79] and it is also considered as an important marker of latency [80].

No crystal structure of HBHA has been hitherto reported. Nevertheless, Small angle X-ray scattering and biophysical data provides a low resolution structure showed that HBHA has a dimeric structure that contains three functional domains: a transmembrane domain of 15-20 amino acids, the $N$-terminus of the protein; an $\alpha$-helical coiled region which may be involved in protein oligomerization and a C-terminal region containing methylated lys-pro-ala-rich motifs [81]. It was reported that HBHA interact with host 
components such as cell surface sulfated glycoconjugates and proteoglycans [81, 82] via the HBHA Cterminal domain by establishing electrostatic interactions with epithelial heparan sulphates [81, 83]. Heparan sulphate is a polysaccharide component of proteoglycans found on cell surfaces and it is composed of alternating (1-4)-linked $\alpha$-D-glucosamine (GlcN) and either $\beta$-D-glucuronic acid (GlcA) or $\alpha$-L-iduronic acid (IdoA) residues [81].

HBHA protein sequence of Mycobacterium avium strain 104 was obtained from UniProt database (UniProtKB - A0A0H2ZUZ1, Gene ID: MAV_4675)

https://www.uniprot.org/uniprot/A0A0H2ZUZ1 and the amino acid sequence is organized in the same manner that the HBHA of Mycobacterium tuberculosis organized in that literature [81] to Figures out each domain and how could it interact with CoV-D (Fig. 5).

\begin{tabular}{|c|c|c|c|c|}
\hline \multicolumn{2}{|c|}{ TM } & \multicolumn{3}{|c|}{ Coiled coil domain (N domain) } \\
\hline 10 & 20 & 30 & 40 & 50 \\
\hline MAENPNIDDL & RAPLLAALGA & ADLALATVND & LIANLRERAE & ETRAETRTRV \\
\hline \multicolumn{5}{|c|}{ Coiled coil domain ( $\mathrm{N}$ domain) } \\
\hline 60 & 70 & 80 & 90 & 100 \\
\hline GERRARLTKF & QEDLPEQFTE & LRDKFTTEEL & RKAAEGYLEA & ATNRYNELVE \\
\hline 110 & 120 & 130 & 140 & 150 \\
\hline RGEAALQRLR & SQTAFEDASA & RAEGYVDQAV & ELTQEALGTV & ASQTRAVGER \\
\hline \multicolumn{5}{|c|}{ Heparin binding domain (C domain) } \\
\hline 160 & 170 & 180 & 190 & 194 \\
\hline AAKLVGIELP & GKAEAAGKKAQ & KАIAKАРАКК & АРАККАРАКК & APAKKАAАKKVTQK \\
\hline
\end{tabular}

Fig. 5. Gene sequence of HBHA of M. Avium

Exploring the structure of the spike protein CoV-D (Fig. 6), it could be detected that the amino acid sequence (676-686) mimics the structure of heparan sulphate but instead sulphate, there is another negatively charged atom; Phosphate at S680. Assuming the co-existence of CoV-D and M. Avium, HBHA 
C-terminal of $M$. Avium could react with $\mathrm{CoV}$ - D at this site through electrostatic interactions of zwitterionic amino acids such as proline, alanine or lysine (Fig. 4S) with the negatively charged phosphate. It is proposed here that the C-terminal domain of M. Avium will bind to position 681 at the spike protein of CoV-D through one of the proline amino acids in this domain. Reviewing the literature, L-proline has been found to act as a weak agonist of the glycine and ionotropic glutamate receptors [84, 85]. Proline residues reported also to have a unique roles in protein folding, structure, and function due to their conformational restriction, the absence of a hydrogen bond donor on the amide, and their special susceptibility to form a cis amide bond [86]. Hence, the source of proline amino acid at position 681 of spike protein of CoV-D is the HBHA of M. Avium. The distinctive cyclic structure of proline's side (Fig. 4S) chain gives proline an exceptional conformational rigidity that affects the secondary structure of proteins near a proline residue and may account for the thermophilic nature of proteins with proline residue [87].

2- Second scenario: Short polyproline motifs (domains that resemble the PXXP motif of human Piccolo protein) were detected in proteins from $M$. avium. This could make us speculate that these motifs could interact with SH3-containing proteins from the host to modulate its cell signaling pathways [88]. The yeast Saccharomyces cerevisiae was reported to have a proteome includes 29 SH3 domains distributed in 25 proteins [89]. A suggested mechanism is that SARS-CoV-1 through interaction with Saccharomyces cerevisiae created a SH3 like domain through molecular mimicry of yeast domains which enabled it later to interact with a proline rich motifs (PXXP) of $M$. avium that led to insertion of proline at that site. Molecular mimicry is one of the strong strategies that enables a pathogen to colonize their hosts and enforce their replication and dissemination. Several viruses have gained the ability of interaction with host cell through protein short linear motifs (SLiMs) that mimic host SLiMs, thus facilitating their internalization and the manipulation of a wide range of cellular networks [90]. For example, the polyproline PxxPxR motifs; Nef and 5A protein (NS5A) found in the (HIV-1) and in the hepatitis C virus respectively. These motifs are able to interact with the SH3 domains of various host cellular proteins [90-92]. 


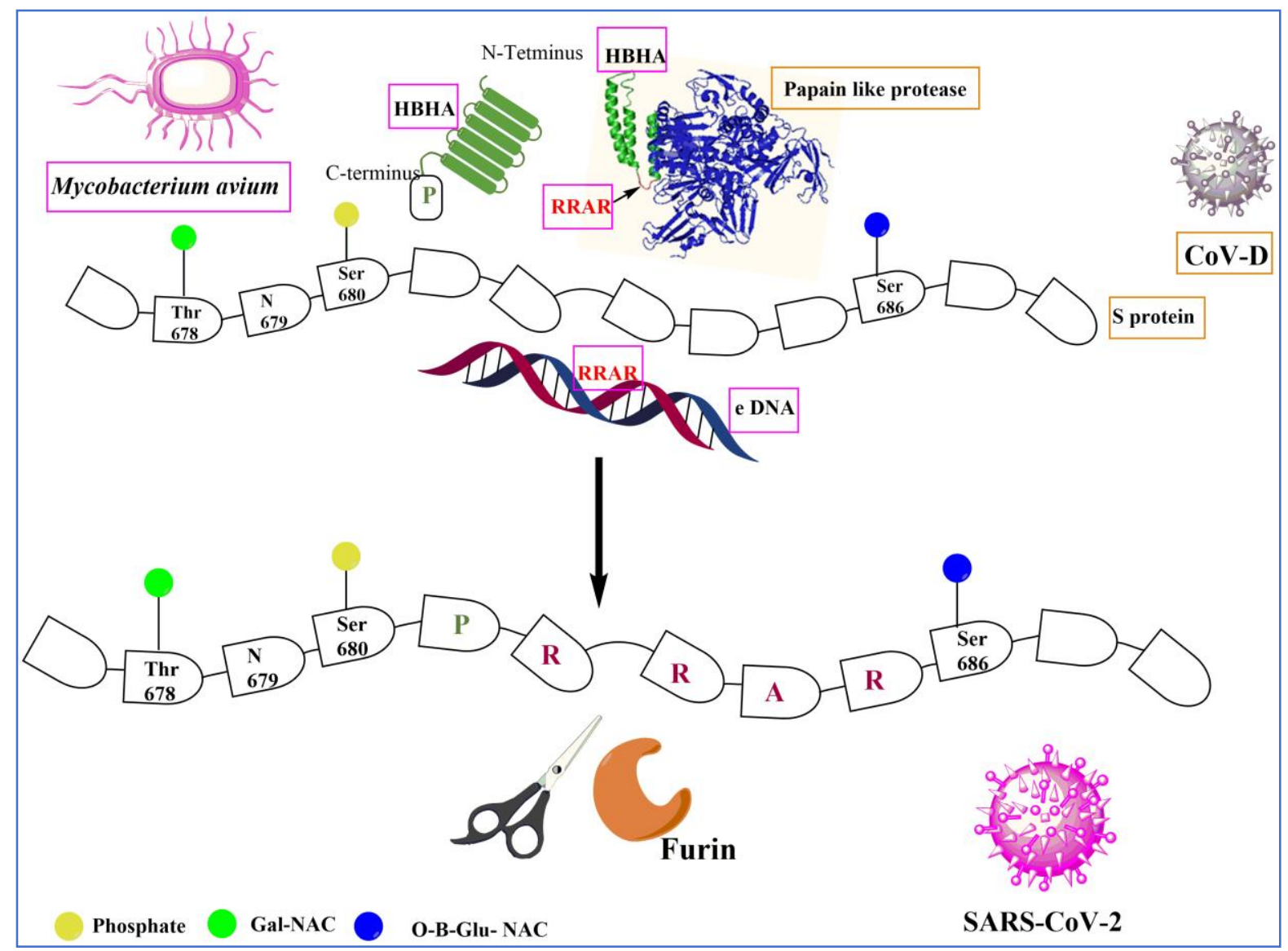

Fig. 6. Interaction between M. Avium and CoV-D

b) Introduction of RRAR amino acid sequence (Arg682, Arg683, Ala684 and Arg685) at S1/S2 fusion site of CoV-D

Three scenarios are suggested for the insertion of this fragment (Fig. 6).

First scenario: HBHA expresses hemagglutination activity, a process correlated to interactions between HBHA molecules on the surface of mycobacteria. Hemagglutination has been correlated with the ability of the N-terminal region of HBHA to form multimers [93, 94]. Proline residue at position 681 in CoV-D could act as a helical kink to which the amino acid (53-56) sequence; RRAR in $\mathrm{H} 2$ helix of the $\mathrm{N}$-terminus of another HBHA is attached.

Second scenario: It was mentioned earlier in this article that $M$. Avium biofilm matrix is associated with extracellular DNA (e-DNA) [73]. Extracellular DNA hypothetical protein of Mycobacterium avium sequence was obtained from NCBI (52 aa protein Accession: WP_155267866.1 GI: 1779430880), 
(https://www.ncbi.nlm.nih.gov/search/all/?term=WP_155267866.1\%20\%20\%E2\%80\%8E), (Fig. 7). It could be inserted beside the proline residue introducing RRAR sequence.

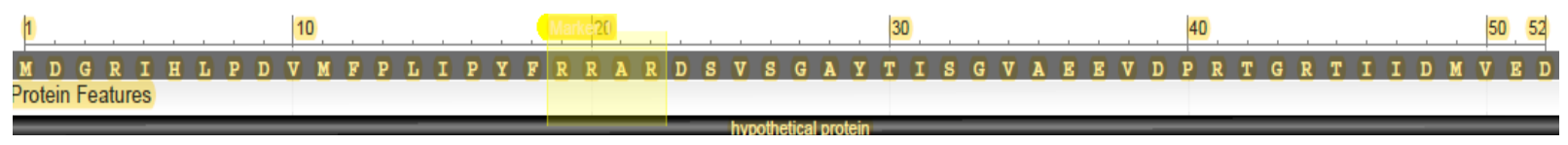

Fig. 7. Amino acid sequence of hypothetical protein of e-DNA of M. Avium

Third scenario: This is the most probable one. Once a molecule of HBHA protein binds to the spike protein of CoV-D while introducing the proline residue, this triggers the release of viral proteases to get rid of this adhesin. CoV-D released one of its proteases named Papain like protease. During this, another molecule of HBHA bonded to this protease exposing the RRAR sequence and when it induces the proteolysis of the first attached HBHA, the RRAR sequence was inserted beside the proline atom due to HBHA-HBHA interaction as described in the first scenario. In a trial to illustrate this; the crystal structure of HBHA of Mycobacterium Avium strain 104 (UniProtKB - A0A0H2ZUZ1, Gene ID: MAV_4675) was processed by SWISS-MODEL online server [95] that produce nine models. The obtained 3D crystal structure of model 09 was marked and visualized using PyMol [96], it was aligned in part with the crystal structure of Papain like protease of SARS-CoV-2 (PDB: 6W9C) (Fig. 8).

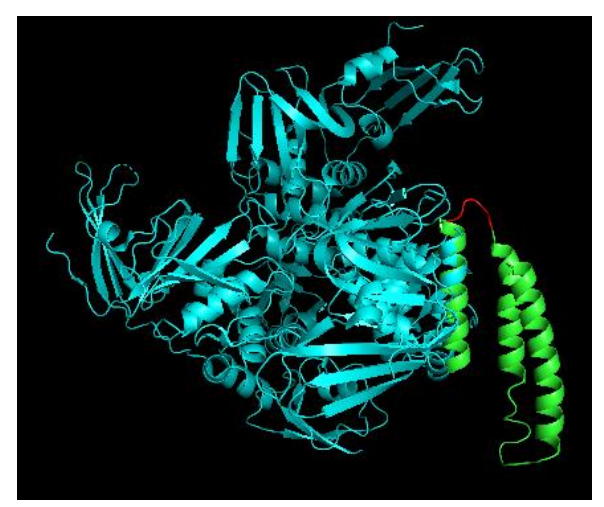

Fig. 8. Alignment of HBHA of M. Avium with Papain like protease of SARS- CoV-2 Using PYMOL

*Green motifs represent HBHA (aa 33-110); and RRAR sequence colored red. Papain like protease (PDB: 6W9C) represented by Pale blue motifs. Sequence 44-52 of HBHA is aligned with sequence 135- 142 of 6W9C. 


\section{c) Introduction of LxxIxE-like motif (LDPLSE) at S1subunit of spike protein}

This ensures the hypothesis of hybridization of SARS-CoV-1 like virus in pangolin with Mycobacterium avium strain 104 due to the presence of such motifs. As previously mentioned, LIDLQE motif in S2 subunit [46] reported in both SARS-CoV-2 and SARS-CoV-1 which ensure that the initial coronavirus that was manipulated inside pangolin was SARS-CoV-1 or a closely related species. LDPLSE is a unique motif present only in SARS-CoV-2 while it is absent in other viruses in the same family [46]. SARS-CoV-2 probably acquired this sequence through interaction with Mycobacterium avium. A conserved hypothetical protein of Mycobacterium avium strain 104 amino acid sequence was obtained from NCBI https://www.ncbi.nlm.nih.gov/protein/ABK66305.1?report=fasta , it contains the same sequence (Fig. 9)

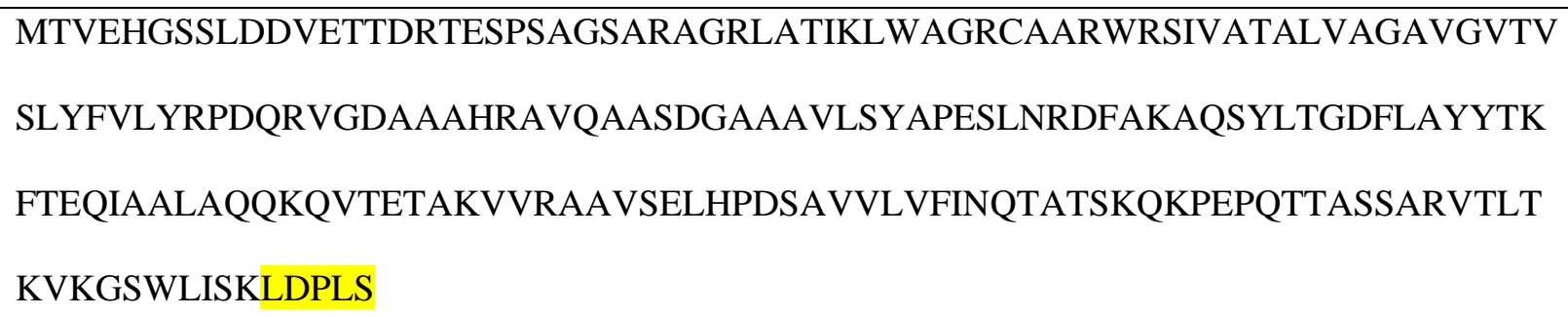

Fig. 9. aa sequence of conserved hypothetical protein of M. avium contains the LxxIxElike motif (LDPLS)

\section{4- Furin cleavage}

The spike protein of SARS-CoV-2 has a functional polybasic (furin) cleavage site (RRAR) at the S1-S2 boundary [44]. Furin is a proprotein convertase subtilisin/kexin (PCSK) enzyme, which is highly expressed in Th1 type cells [97]. In general, PCSKs convert proproteins into their biologically active forms by cleaving them at specific target motifs made up of the basic amino acids lysine and arginine [98]. Upregulated furin A expression can serve as a marker for mycobacterial disease, since it inhibits early host responses and consequently promotes bacterial growth in a chronic infection [97]. This fact completes the whole picture of the hypothesis of recombination with M. Avium. If a pangolin co-infected with M. Avium and $\mathrm{CoV}$, it will express high level of furin that will break the polybasic (RRAR) site at the S1-S2 boundary 
of the S protein in CoV-D and that resulted in the final form of this virus which is SARS-CoV-2. It is important here to note that furin enzyme was reported to be found at Malayan pangolin (Gene ID: 108385790) [99] and this fact ensure that the SARS-CoV-2 was transmitted to humans from pangolins not bats which lacks the furin enzyme.

(iii) Comparative study for the diseases pattern caused by SARS-CoV-2, Saccharomyces cerevisiae and Mycobacterium avium.

At any chemical reaction, the product may have similar or different characters compared to the original substrates. This concept could be implemented at this microbial interaction; the produced final microorganism (SARS-CoV-2) may have similar or different characters compared to the organisms shared in its production; Saccharomyces cerevisiae and Mycobacterium avium.

To can figures out this similarities or differences, a comparative study for the diseases caused by the three organisms; SARS-CoV-2, Mycobacterium avium and Saccharomyces cerevisiae was carried out. The comparative study showed similarity between the three disease and it includes the etiology (Table S1), symptoms (Table S2), clinical manifestations (Table S3), complications (Table S4), mode of transmission (Table S5), epidemiology (Table S6), herd susceptibility (Table S7), host cell interaction (Table S8), (Figs. 5S-7S), diagnosis (Table S9), (Fig. 8S) and treatment (Table S10) of the disease caused by each microorganism. This could be a useful tool for understanding the abnormal clinical findings of COVID-19 disease and as well it could be a prospective way to find a treatment or vaccine.

\section{Results and discussion of facts concluded from the hypothesis and the comparative study}

SARS-CoV-2 is not just a virus, it is a cocktail microorganism that contains a viral RNA encapsulated within a glycan shield with fungal and bacterial epitopes that was manipulated by yeast and Mycobacterium avium. It could be considered as activated or accelerated yeast infection or could also considered as active 
or replicating SARS vaccine. The fungal and bacterial origin of SARS-CoV-2 could explain and figures out most of the current unexplained findings for COVID-19 disease.

1- COVID-19 is a contagious disease with a genetic predisposing factor

It is discussed earlier in this text that SARS-CoV-2 and Mycobacterium avium have similar antigenic epitopes ( $\alpha$-mannan glycans) (Figs. 1 and 3S). Mycobacterium avium infection has been reported from the Americans, Asian, and European patients [100] [101]. Other mycobacterial infections like Mycobacterium tuberculosis disease have the same epidemiology.

In the first half of the 19th century, tuberculosis peaked in Europe and one-quarter Europeans died of TB. Several studies referred to the role of human phenotypic traits, like lactose intolerance to be one of the reasons for which it was spread at Indo-European at that time [102]. Lactose intolerance (LI) is an interesting point to predict the ethnicity and hereditary factor for people who are more susceptible for SARS-CoV-2 infection. It is estimated that about $70 \%$ of the world population is affected by LI with great variation among ethnicities and races [103].

Recent publication discussed the increased prevalence of lactose mal absorption in the elderly due to clinically unapparent small intestinal bacterial overgrowth, rather than any subtle, age-related mucosal factors [104]. This could explain the prevalence of SARS-CoV-2 infection in elderly patients [105]. Beside the other risk factors such as the low immunity and chronic diseases, if we look to COVID-19 disease from LI notion, this could give an explanation for the prevalence of SARS-CoV-2 in older adult's population and in certain families with different ages as well as certain countries.

As reported by WHO [106], three ethnicities showed higher vulnerability for infection and were reported for the highest number of cases all over the world; Chinese, American and European (specially in Italy and Spain). Several studies reported LI in Chinese populations of all ages [107, 108]. More recent study showed that $100 \%$ of Chinese showed lactase non-persistence [109]. LI also was reported among Europeans in several studies. For example; many studies discussed the LI among older Italian adults [110, 111]. In Spain, IRISH Food Board reported that $34 \%$ of the Spanish population are lactose-intolerant [112]. Moreover, In the USA, there is LI in 70 to $80 \%$ of Whites of European or Scandinavian extraction, $30 \%$ of 
Mexicans, and 20\% of African Americans [109]. While in countries like India showing a decline in the LI and it is only in some milk consuming nomads [109], where the rate of COVID-19 spread is limited.

Regarding Lactose intolerance, more information are needed for such potential association with SARS-CoV-2, no published data up to now about such possibilities and this hypothesis still need more clinical investigation and testing throughout the infected cases to confirm or counteract this likelihood correlation.

This hypothesis could also explain the reason for which blood group A was associated with a higher risk for acquiring COVID-19 [113] and as well the prevalence of vitamin D insufficiency in severe COVID19 cases [114]. A group of researchers at the University of Toronto's Faculty of Medicine in Canada published a recent research stating that $\mathrm{LI}$ is associated with a lower plasma vitamin $\mathrm{D}$ concentration [115]. And as well, the correlation between blood type A and dairy products such as milk and cheese were discussed by many dietitians who described milk and other dairy products as the first diet enemy for people with blood type A. They owed the reason was due to many type A individuals have some degree of lactose intolerance, due to insufficient levels of lactase enzyme and then type A blood people creates antibodies to the indigestible sugar in dairy products [116]. Another predisposing factor for the spread of COVID-19 infection among the blood type A population is that the type As have a naturally high level of the stress hormone cortisol and produce more in response to stressful situations [116]. Cortisol is immunosuppressive in function, and elicits its immunosuppressive effects by downregulating key inflammatory transcription factors, NF-kB and AP-1, and upregulating the suppressor of cytokines [117].

\section{2- SARS-CoV-2 could form a biofilm like structure}

Biofilm formation is a common phenomenon in bacteria and fungi and it was reported that Mycobacterium avium [72] and Saccharomyces cerevisiae [72, 118] have the ability to form a biofilm while a few or limited data are available on the ability of viruses to form a biofilm. HTLV-1 retrovirus is one of limited examples that was reported for its ability to form a biofilm like structures on the surface of infected cells [119]. The aggregates of HTLV-1 viruses embedded in a carbohydrate-rich structure containing cellsecreted extracellular matrix that may protect viruses from the immune system and enable them to spread 
efficiently from cell to cell. Extracellular matrix (ECM) components, including collagen, some specific heparan sulfate proteoglycans such as agrin, and several linker proteins such as galectin-3 and tetherin, were found to be enriched in these structures [119]. Comparing SARS-CoV-2 to HTLV-1 retrovirus, it is clear from the virus structure that SARS-CoV-2 genome is encased into a carbohydrate-rich adhesive extracellular 'cocoon', and also it has a proteoglycan like site (at S1/S2 fusion site in the spike glycoprotein) that provide a possibility for cell to cell transmission and formation of a biofilm like structure which enables its efficient and protected transfer between cells. Biofilm like structure could serve for the rapid transmission between individuals and inside the host cells, dissemination of the virus inside the host infecting several organs, relapse of infection, resistance to medication and longtime stability over a nonliving surface. Two recent publications about SARS-CoV-2 could support the hypothesis of the biofilm formation but this still need a laboratory confirmation. One study discussed the aerosol and surface longer stability of SARS-CoV-2 compared with SARS-CoV-1 [120]. The second study discussed the presence of SARS-CoV-2 in the urban water cycle and they owed the reason to many factors one of which is that the virus could colonize the bacterial biofilm [121].

The ability of the virus to form a biofilm is a good therapeutic target. The use of antibiofilm agents could be one of the therapeutic strategies applied for the treatment. Antibiofilm activity hypothesis could rationalize the French clinical therapeutic approach using Azithromycin [122] and explains its mechanism of action against SASR-CoV-2. Azithromycin has been reported for its antibiofilm activity through inhibiting the quorum sensing [123]. Several agents has been reported as antibiofilm agents with different mechanism of action such as quorum sensing inhibitors, biofilm matrix degrading enzymes, antimicrobial peptides, surfactants, free fatty acids, amino acids, nitric oxide generators, indole and its derivatives, anthranilate and metal chelators [124]. Accordingly, the current drug development trials are recommended to take into consideration the incorporation of antibiofilm agent into the supposed treatment formula. 
3- MERS (Middle East respiratory syndrome) coronavirus could be initiated through microbial interaction between Mycobacterium tuberculosis and SARS-CoV-1 virus

Previous research detected that spike protein of MERS contains a putative furin recognition motif (PRSV) [45, 125]. Mycobacterium tuberculosis infections in camels has been reported in many publications [126-128]. A possible mechanism of interaction includes (i) humanization of SARS-CoV inside camel's Golgi providing glycosylated sites that are similar to proteoglycans. And as a result, this site could bind to HBHA molecule of Mycobacterium tuberculosis introducing a proline residue at that site. The sequence (RSV) could be then introduced through interaction with a ribosomal RNA methyltransferase (TlyA) which contain this sequence (UniProtKB, P9WJ63) encodes for a protein named: 16S/23S rRNA (cytidine-2'-O)methyltransferase (TlyA), (Fig. 9S).

https://www.uniprot.org/uniprot/P9WJ63. This hypothesis still needs more investigation.

4- The participation of Saccharomyces cerevisiae in the structure of SARS-CoV-2 explains some of the abnormal clinical findings such as:

\section{1-Kawasaki-like Syndrome among children}

Since April 15, many European countries have reported the arrival of a surprisingly high number of children (3-17 years old) with symptoms similar to Kawasaki disease in intensive care of their hospitals [129] with no previous risk factors such as obesity or cardiac diseases. These cases showed symptoms of fever and abdominal pain or vomiting. Sometimes they had a very fleeting rash and presented with cardiac and circulatory failure. All the children needed ventilatory support, even if they did not have pulmonary disease. PCR test for SARS-CoV-2 among those cases was weak positive showing that they were infected 3-4 weeks before the appearance of symptoms [129].

The Saccharomyces cerevisiae infection among children was reported in many publications [130, 131] nearly showed the same symptoms diagnosed in children with SARS-CoV-2. One case (31/2-monthold male infant) of Saccharomyces cerevisiae infection showed symptoms of fever, watery diarrhea, erythematous macular skin rashes over the trunk and limbs, enlarged liver, few discrete palpable lymph 
nodes in the cervical region [132]. Other more severe cases developed sever reaction like septic shock [133], infective endocarditis, progressive renal, hepatic and pulmonary failure [134].

Kawasaki-like symptoms among children infected with SARS-CoV-2 is due to the presence of Saccharomyces cerevisiae antigenic glycans over the surface of SARS-CoV-2 virus and this is one of points that could proof the hypothesis of the origin of COVID-19 disease generated in this article.

\section{2- Skin hyper pigmentation of two Chinese physicians}

A lot of newspapers and TV channels all over the world discussed the anomalous finding that happened to Yi Fan and Hu Weifeng; two Chinese doctors who were infected with SARS-CoV-2 while treating patients in the city of Wuhan, but their skin turned very dark after they were placed on life support, according to a report. Many physicians owed that to their liver's impairment and accumulation of iron due to infection based on the recent research that have discussed the effect of SARS-CoV-2 on liver cells. This could be a reasonable theoretical explanation but when we think in a realistic way it is not. More pathogenic liver specific viruses such as Hepatitis (B and C) viruses and even in the late stage of disease, when all the liver cells become fibrotic, such level of hyper pigmentation was not reported in hepatitis patients. The proposed origin of SARS-CoV-2 could provide an answer to this outstanding question.

A strange but more reasonable answer is the ability of the virus to synthesize melanin as a protective mechanism against ultraviolet irradiation for example. This still a theoretical explanation and it needs a laboratory investigation. Many fungal species produce melanin as a mechanism of resistance to environmental damage such as from ultraviolet radiation [135]. Studies with animal models demonstrate that melanin is a virulence factor responsible for dissemination in several fungal pathogens [135]. Previous studies reported some yeast species as a melanogenic yeast specially in the presence of DOPA but not the Saccharomyces cerevisiae $[136,137]$

It is particularly important to investigate the ability of SARS-CoV-2 to form melanin especially after exposure to UV light which threatens infected medical team and if this comes true, COVID-19 patients should avoid prolonged exposure to sunlight. 
5- The participation of Mycobacterium avium in the structure of SARS-CoV-2 explains the disseminated intravascular coagulation in COVID-19 patients

Blood from $20 \%$ to $30 \%$ of critically ill COVID-19 patients clotted in the tubes when nurses insert catheters for kidney dialysis and IV lines to draw blood as reported in many hospitals [138-140]. Several hospitalized patients have drastically elevated levels of a protein fragment called D-dimer, which is generated when a clot dissolve. High levels of D-dimer appear to be a powerful predictor of mortality in hospitalized patients infected with SARS-CoV-2 [141].

Since the year 2017, many publications reported the disseminated intravascular coagulation (DIC) as well as elevated D-dimer level in Mycobacterium avium complex infections [142-146]. Elevated D-dimer level has been also reported as a marker for infection with Mycobacterium tuberculosis [147]. It is reported that Glyceraldehyde 3-phosphate dehydrogenase (GAPDH) of Mycobacterium avium bind to fibrinogen (Fn) [148]. Assuming that SARS-CoV-2 has a portion like GAPDH acquired through microbial interaction, so it will be able also to bind to fibrinogen.

Fibrinogen is a glycoprotein complex that is converted enzymatically by thrombin to fibrin and then to a fibrin-based blood clot during tissue and vascular injury $[149,150]$. Thrombin is a as a serine protease enzyme catalyzing many coagulation-related reactions [151].

It is reported that SARS-CoV-2 has a serine protease enzymes [152] that could play the same role of thrombin when the virus bonded to fibrinogen and activates the conversion of fibrinogen to fibrin clots but this still need a laboratory and clinical investigation.

\section{Conclusions, Recommendations and future perspectives}

1) The human contact with pangolins through food or medical formulas should be halted and as well, yeast should not be applied as ingredient in the food formula provided to pangolins at captive breeding reservoirs. 
2) Treatment: The bacterial and yeast share in the structure of SARS-CoV-2 could be a way to predict a treatment strategy. Up to date, some antibacterial drugs were tested against SARS-CoV-2 and showed activity such as Azithromycin, but no trial were done using the antifungal medications. Depending on the hypothesis initiated in this article, it is recommended to start a clinical trials as well as a drug-drug interaction study with a triple therapy consist of antiviral (e.g. Remdesivir) + antibacterial (e.g. Aithromycin) + antifungal (e.g. fluorocytosine and/or Micafungin) medications. The incorporation of antibiofilm agent in the drug formula is important to enhance the efficiency and reduce the resistance to treatment.

3) Vaccine or immunoprotecting: The use of saccharomyces cerevisiae supplement as immunostimulant and protectant against SARS-CoV-2 as well as the development of yeast-based vaccines is highly recommended to be studied as a result of this hypothesis.

4) It is recommended to perform lactose intolerance test for all hospitalized patients to figures out this risk factor which could be a useful diagnostic test to investigate the vulnerability to infection for people who have risk factors such as compromised immunity or chronic diseases or even for healthy person.

5) Laboratory investigation of the ability of virus to form a biofilm as well as the melanogenic activity of SARS-CoV-2. This investigation is important for the therapeutic incorporation of antibiofilm agent in the medication and for the avoidance of patients to exposure to ultraviolet radiation.

\section{Declaration}

- Ethical Approval and Consent to participate: No animal experiments or clinical trials were performed.

\section{- Availability of supporting data}

File 1: Comparative study for the diseases caused by the three organisms; SARS-CoV-2, Mycobacterium avium and Saccharomyces cerevisiae. Etiology (Table S1), symptoms (Table S2), clinical manifestations 
(Table S3), complications (Table S4), mode of transmission (Table S5), epidemiology (Table S6), herd susceptibility (Table S7), host cell interaction (Table S8), (Figs. 5S-7S), diagnosis (Table S9), (Fig. 8S) and treatment (Table S10).

File 1: supplementary figures

Fig. 1S Structure of S glycoprotein of SARS-CoV-1.

Fig. 2S Glycolysis of sugars in Saccharomyces cerevisiae.

Fig. 3S Glycan structure of Mycobacterium avium.

Fig. 4S Structure of amino acids in C-terminus of HBHA of M. Avium.

Fig. 5S SARS-CoV-2 host cell interaction.

Fig. 6S Saccharomyces cerevisiae host cell interaction

Fig. 7S Mycobacterium avium host cell interaction

Fig. 8S Lung CT scan examination

Fig. 9S Amino acid sequence of 16S/23S rRNA (cytidine-2'-O)-methyltransferase (TlyA)

- Competing interests: The author declares no competing interests.

- Funding: No fund applied to this article.

- Authors' contributions: Single author: designed the hypothesis and wrote the manuscript. 


\section{Supplementary materials, Tables}

Table S1: Etiology

SARS-CoV-2 It is a positive-stranded RNA virus with a crown-like appearance due to the presence of spike glycoproteins on the envelope. It belongs to Coronaviridae family which contains several CoVs that are classified into four types: Alpha, Beta, Delta, and Gamma coronaviruses. SARS-CoV-2 belongs to Beta-coronaviruses. [153].

\begin{tabular}{|c|c|}
\hline Saccharomyces cerevisiae & $\begin{array}{l}\text { Also known as "baker's yeast" or "brewer's yeast". It is a non-spore forming yeast that is widespread } \\
\text { in nature and can be found on plants and fruit and in soil. It is mostly considered to be an occasional } \\
\text { digestive commensal. S. cerevisiae is now included in some diet or health foods as well as some } \\
\text { supplements or medications such as probiotic preparation containing Saccharomyces boulardii, a } \\
\text { subtype of S. cerevisiae, used for the prevention and treatment of various diarrheal disorders. Since the } \\
\text { 1990s, there have been a growing number of reports about the implication of S. cerevisiae as an } \\
\text { etiologic agent of invasive infection association with a probiotic preparation of Saccharomyces } \\
\text { boulardii (a subtype of S. cerevisiae) for treatment various diarrheal disorders [154]. S. cerevisiae is } \\
\text { now considered an emerging opportunistic pathogen that has been related to a wide variety of } \\
\text { infections, which range from vaginitis and cutaneous infections, to systemic bloodstream infections } \\
\text { and infections of essential organs in immunocompromised and critically ill patients [155]. Several } \\
\text { studies reported Saccharomyces cerevisiae associated pneumonia in immune-compromised patients } \\
\text { [156-158]. }\end{array}$ \\
\hline Myco & $\begin{array}{l}\text { It usually present as a complex with Mycobacterium intracellulare (MAC) because these species are } \\
\text { difficult to differentiate [159]. M. avium complex is a nonmotile, slow-growing, non-spore-forming, } \\
\text { gram-positive acid-fast bacillus, thermostable and can survive up to } 499^{\circ} \mathrm{C} \text { [159]. M. avium is } \\
\text { composed of four named subspecies: M. avium subspecies Avium, M. avium subspecies silvaticum, M. } \\
\text { avium subspecies paratuberculosis, and M. avium subspecies hominissuis. It was reported that the } M \text {. } \\
\text { avium subspecies avium are responsible for pulmonary infections and the } M \text {. }\end{array}$ \\
\hline
\end{tabular}


avium subtype hominissuis appears to be gastrointestinal in origin. M. avium subspecies paratuberculosis was identified in ruminants as a causative agent for Johne disease [159, 160].

\section{Table S2: Symptoms}

SARS-CoV-2 The most common symptoms include fever, fatigue, and dry cough and shortness of breath. Less common symptoms include pharyngitis, headache, productive cough, GI symptoms and hemoptysis [161].

Saccharomyces cerevisiae $\quad$ Fever, diarrhea, laryngitis and oral lesions $[162,163]$.

\section{Mycobacterium avium MAC infections symptoms depending on the site of the infection.}

- The symptoms of pulmonary MAC infection include cough, weight loss, fever, fatigue, and night sweat [164].

- Disseminated MAC Symptoms include: Fever, sweating, weight loss, fatigue, diarrhea, abdominal pain, shortness of breath, anemia mastitis; pyomyositis and abscesses of the skin or brain $[165,166]$.

- MAC lymphadenitis generally affects children who have normal immune systems. Symptoms usually only include swollen lymph nodes mainly on one side of the neck $[165,166]$. 
Table S3: Clinical manifestations

SARS-CoV-2 The clinical spectrum of COVID-19 varies from asymptomatic forms to clinical conditions characterized by respiratory failure that necessitates mechanical ventilation and support in an intensive care unit (ICU), to multiorgan and systemic manifestations in terms of sepsis, septic shock, and multiple organ dysfunction syndromes (MODS) [153].

\begin{tabular}{ll}
\hline Saccharomyces cerevisiae & S. cerevisiae can cause a wide variety of clinical syndromes such as: \\
& $\begin{array}{l}\text { Pneumonia [34-36], Empyema [36, 167], Liver abscess [34-36], Peritonitis [36, 168], Vaginitis [36, } \\
\text { 169], Esophagitis [35, 36], Urinary tract infection [36, 170], Cellulitis [36, 171], Unexplained fever, or } \\
\text { septic shock [36, 167]. }\end{array}$ \\
\hline Mycobacterium avium & MAC infections were classified to three types: \\
& - Pulmonary MAC infections (the most common type), that usually affect the lungs of elderly women \\
& and people who already have diseased lungs [164],[166]. \\
& - Disseminated MAC infections, affect all organs throughout the body usually of AIDS patients [165]. \\
& MAC associated lymphadenitis, characterized by neck lymph nodes swelling in young children \\
& who have normal immune systems [166, 172].
\end{tabular}


Table S4: Complications

SARS-CoV-2

Saccharomyces cerevisiae
- Complications included acute respiratory distress syndrome, RNAaemia, acute cardiac injury and secondary infection. $32 \%$ of patients were admitted to an ICU and $15 \%$ of them died [173].

- $40 \%$ cases showed loss of sense of smell in adults (Post-viral anosmia)[174].

- Moreover, relapse of infection was reported [175].

Infectious endocarditis [176, 177], infection of an aortic-bifemoral graft in some cases who developed aorto-enteric fistula and finally died of the infection [178].

Mycobacterium avium

- Anemia and weight loss are the most common complications reported with DMAC infection [179].

- High rates of morbidity and mortality were reported among HIV-infected patients with DMAC infections [179].

- Patients with more extensive disease have a $20 \%$ chance of relapse after treatment with anti-MAC drugs [179].

- Death could be a major complication for untreated patients with significant lung disease [179].

- Chronic Rhinosinusitis is also a known complication despite the use of antimicrobial drugs and sinus irrigation, $90 \%$ of patients had a persistent chronic symptoms such as headache, nasal congestion and decreased ability to taste or smell [180]. 


\section{Table S5: Mode of transmission}

SARS-CoV-2 Currently the main transmission routes are respiratory droplets and contact transmission. Recent reports indicate that SARS-CoV-2 can be detected in the urine and stool of laboratory confirmed patients, implying a risk of fecal-oral transmission. There is still no evidence that SARS-CoV-2 can be transmitted from mother to baby during pregnancy or childbirth [181].

Saccharomyces cerevisiae From abuse of probiotic preparations. It could also be transmitted in hospitals ICU (nosocomial acquisition) with catheters [154]. Transmission through hand was also reported [182, 183].

\begin{tabular}{ll}
\hline Mycobacterium avium & MAC bacteria get into the body through inhalation of aerosol particles or ingestion of contaminated \\
& water [72,184]. Touching the same objects or having a close relationship with people who are sick \\
& from a MAC infection does not increase the infection. MAC infections was not considered as a \\
& contagious bacteria between persons [166].
\end{tabular}

\section{Table S6: Epidemiology}

SARS-CoV-2 The initial outbreak (December 2020) only occurred in Wuhan, Hubei Province, China. COVID-19 had spread to all 31 provinces of China. It spread through all continents and declared as a pandemic by the World Health Organization (WHO) on March 11, 2020. The most affected continents are Asia, Europe and America [185].

\begin{tabular}{ll}
\hline Saccharomyces cerevisiae & $\begin{array}{l}\text { The incidence of Saccharomyces fungemia varied from } 1 \% \text { to } 3.6 \% \text { in a retrospective study of } 102 \\
\text { nosocomial cases of fungemia among patients at French teaching hospitals [154, 186]. }\end{array}$ \\
\hline Mycobacterium avium & $\begin{array}{l}\text { Mycobacterium avium complex is ubiquitous and has been reported from the Americas, Asia, and } \\
\text { Europe [100, 101]. }\end{array}$
\end{tabular}


SARS-CoV-2 Sex ratio: (52\%) men and (48\%) women [187].

Age: All ages could be infected but it is more common in elder people $\geq 60$ years [188].

Risk factors: Older adults and people of any age who have serious underlying medical conditions; chronic lung disease or moderate to severe asthma; serious heart conditions; immuno-compromised due to cancer treatment, smoking, bone marrow or organ transplantation, immune deficiencies, poorly controlled HIV or AIDS, and prolonged use of corticosteroids and other immune weakening medications; severe obesity (body mass index $[\mathrm{BMI}] \geq 40$ ); diabetes; chronic kidney disease undergoing dialysis and liver disease [189].

Mortality: Mortality rate is age dependent. Aged $<60: 1.38 \%$, Aged $\geq 60$ years: $6.4 \%$, Aged $\geq 80$ years: $13.4 \%$ [188].

\begin{tabular}{ll}
\hline Saccharomyces cerevisiae & Sex ratio: Sex ratio was 0.74 (35 females and 47 males) out of 92 studied cases [154]. \\
& Age: Age $\geq 60$ years are most infected [36]. \\
& Risk factors: $S$. cerevisiae fungemia has been described in immunosuppressed patients and critically \\
& ill patients but also in relatively healthy host [36]. Underlying conditions include cancer, HIV infection, \\
& use of corticosteroids, neutropenia, bone marrow transplantation, solid organ transplantation, burns and \\
& heart surgery [190-195]. Critically ill neonates seem to be particularly predisposed to fungemia [134]. \\
& Mortality: The mortality rate was 28\%. The only factor that increased the mortality rate was older age \\
& [36]. \\
& Sex ratio: some studies revealed that women had a higher prevalence, up to 1.6-fold relative to men \\
& while other studies has shown a higher male prevalence (2:1) [159]. \\
& Age : Age $\geq 70$ years are most infected [67]. \\
& Risk factors: Immune-compromised populations, such as patients with cystic fibrosis, chronic \\
obstructive pulmonary disease, renal failure, transplant recipients with chronic corticosteroid use and
\end{tabular}


TNF- $\alpha$, and leukemia [68, 69]. Some studies showed the importance of patient genetics in the infection vulnerability. A persons with Lady Windermere syndrome and patients with genetically determined defects of cell-mediated immunity such as abnormalities of the interleukin-12/interferon- $\gamma$ axis, certain human leukocyte antigen alleles, cystic fibrosis transmembrane conductance regulator mutations, and polymorphisms of solute carrier 11A1 (or natural resistance-associated macrophage protein 1) and the vitamin D receptor are more susceptible to be infected by non-tuberculous mycobacterium [196].

Mortality: A study measures the estimate of five-year all-cause mortality was $27 \%$ indicating a poor prognosis for patients [67]. 
SARS-CoV-2 • Human ACE2 was found to be a receptor for SARS-CoV-2 [42, 43].

- SARS CoV-2 is reported in a recent study to bind to CD209, a C-type lectin that binds to highmannose glycans on glycoproteins, has also been found to be as an alternative receptor for SARSCoV [41], (Fig. 5S).

Saccharomyces cerevisiae

- $\quad \beta$-glucans found in the $S$. cerevisiae cell wall can be directly recognized by Dectin-1 in human DCs which results in activation of TNF $\alpha$, RTKs, ROS production, and NF- $\kappa B$ activation. It induces the expression of immuno-regulatory cytokines, such as (IL)-1 $\beta$, IL-12, IL-6, IL-10, TGF- $\beta 1$, and IL-2 and can promote both Treg and Th17 responses and induce phagocytosis [197-200]. $\beta$ glucans also binds to Surfactant proteins D (SP-D); a calcium-dependent lectin that induced yeast aggregation [201].

N-glycan $\alpha$-mannan binds to C-type lectins; Langerin and SIGNR1 that resulted in comparable amounts of interleukin 10 (IL-10) [202, 203] (Fig. 6S).

Mycobacterium avium

Several adhesion molecules found in Mycobacterium avium which are involved in adherence and promote internalization into the host cells, facilitate bacterial colonization, (Fig. 7S) such as heparinbinding haemagglutinin binds to sulphated surface receptors such as heparin sulphate [204], binding of lipoarabinomannan to CD209, a C-type lectin [205], glyceraldehyde 3-phosphate dehydrogenase (GAPDH) binding to fibrinogen (Fn) [148], adhesion of fibronectin-binding protein (FnBP) to fibronectin [206], isocitrate lyase binding with fibronectin or laminin [207], Antigen-85 complex (85B and MPT51) binding with fibronectin/elastin [208], $19 \mathrm{kDa}$ protein (maltose-binding protein) binds with mannose receptor [209].

Other cell surface exposed proteins such as ATPase, 30S ribosomal protein S1, Argininosuccinate synthase, DivIVA family protein, Glutamine synthetase A1, 3-Oxoacyl synthetase, 3-Oxoacyl sintase 2 B, Phage shock protein A, Aldolase/citrate lyase, Carbamoyl-phosphate synthase subunit A, Shortchain dehydrogenases/reductases, Acyl-CoA dehydrogenase FadE3, 3-Ketoacyl reductase, ATP dependent protease $\mathrm{ClpB}$, GroEL chaperonin and Elongation factor Tu [210]. 
SARS-CoV-2 Radiology: Chest CT may show ground-glass opacities mainly involving the right lower lobes that may evolve into consolidation. Findings appear to peak at $10 \mathrm{~d}$ of illness, resolution begins after day 14, Tree-in-bud signs, masses, cavitation, and calcifications were not observed (Fig. 8S) [161, 187, $211]$.

\section{Laboratory testing:}

RT-PCR assay is used to detect the viral loads in throat swab and sputum samples peaked at around 56 days after symptom onset [212].

Complete blood count (CBC) analysis showed lymphocytopenia (in CD4+ and CD8+ T cells), elevated level of lactate dehydrogenase $(\mathrm{LDH})$, alanine aminotransferase, aspartate aminotransferase, Creactive protein (CRP), ferritin and D-dimer was found in most cases, baseline interleukin-6 (IL-6) and IL-8 were significantly increased in severe type, IL-10 was slightly increased while the baseline level of IL-2, IL-4, TNF- $\alpha$ and IFN- $\gamma$ was within normal range [213-215].

Serologic testing: The IgM-IgG combined assay can be used for the rapid screening of SARS-CoV-2 carriers, symptomatic or asymptomatic [216].

$\begin{array}{ll}\text { Saccharomyces cerevisiae } & \text { Radiology: : CT scan showing evidence of right lower lobe consolidation and pleural effusion, (Fig. } \\ & \text { 8S) }[217,218] . \\ & \text { Laboratory testing: } \\ & \text { Blood cultures grew Saccharomyces cerevisiae that was identified by Matrix Assisted Laser } \\ & \text { Desorption/Ionization (MALDI) mass spectrometry [219]. Another study identified Saccharomyces by } \\ & \text { biochemical tests (API 20C AUX [Biomerieux] and Uni-Yeast-TEK [Remel]) and the presence of } \\ & \text { ascospores as well as sequence analysis of the 18S rRNA gene [178]. }\end{array}$


Complete blood count (CBC) often shows abnormal liver function test (ALP, AST, ALT and total bilirubin), elevated lactate dehydrogenase (LDH) [219]. CBC could show also leukocytosis; hyponatremia, increased creatinine and increased C-reactive protein (CRP) [220].

Serologic testing: ASCA (anti- Saccharomyces cerevisiae antibodies); both IgG and IgA antibodies [221].

Radiology: CT scan showing evidence of right middle lobe (or left lingular lobe) lung infection. It shows bronchiectasis, small nodules, tree-in-bud appearance, ground-glass opacities, and pleural thickening, (Fig. 8S) [222, 223].

Laboratory testing: Diagnostic testing includes acid-fast bacillus (AFB) staining and cultures of sputum, blood, urine, stool and/or cutaneous lesions specimens depending on the type of infection[224].

In patients with DMAC, a complete blood count (CBC) often shows anemia, pancytopenia, leukopenia (lower CD4 cell counts), hypogammaglobulinemia, hypoalbuminemia, may be found. On liver function studies, patients with DMAC usually have elevated transaminase and alkaline phosphatase and lactate dehydrogenase (LDH) levels as well as elevated erythrocyte sedimentation rate (ESR) [224, 225].

Serologic testing: An enzyme immunoassay (EIA) kit used in Japan has been used to detect serum IgA antibody to MAC-specific glycopeptidolipid core antigen [67, 224, 225]. 
SARS-CoV-2 UpToDate, there is no clinically proved effective antiviral treatment nor vaccine is currently available. The treatment is often symptomatic treatment including the oxygen therapy. In cases of respiratory failure, mechanical ventilation may be necessary for managing septic shock. Although no antiviral treatments have been approved, several approaches have been proposed such as lopinavir/ritonavir (400/100 mg every 12 hours), chloroquine (500 mg every 12 hours), and hydroxychloroquine (200 mg every 12 hours). Alpha-interferon (e.g., 5 million units by aerosol inhalation twice per day) is also used [153]. Preclinical studies suggested that remdesivir (GS5734) — an inhibitor of RNA polymerase. could be effective for both prophylaxis and therapy of HCoVs infections [226]. Another drug that showed a promising activity against SARS-CoV-2 is favipiravir [227]. Azithromycin also showed a promising activity in combination with hydroxychloroquine [122].

\begin{tabular}{ll} 
Saccharomyces cerevisiae & Amphotericin B and Fluorocytosine [36, 228], Micafungin and Fluconazole [219]. \\
\hline Mycobacterium avium & $\begin{array}{l}\text { Several medications are used in the treatment of Mycobacterium avium complex infections such as a } \\
\text { macrolide, clofazimine, rifampin, rifabutin, ethambutol, fluoroquinolone, linezolid, and } \\
\text { aminoglycosides. In severe cases including a fibrocavitary disease, a triple oral therapy consists of } \\
\text { azithromycin, rifampin, and ethambutol is prescribed followed by injectable aminoglycoside. Inhaled } \\
\text { amikacin can be used as well [159, 229]. }\end{array}$ \\
\hline
\end{tabular}




\section{Supplementary data, Fig.s}

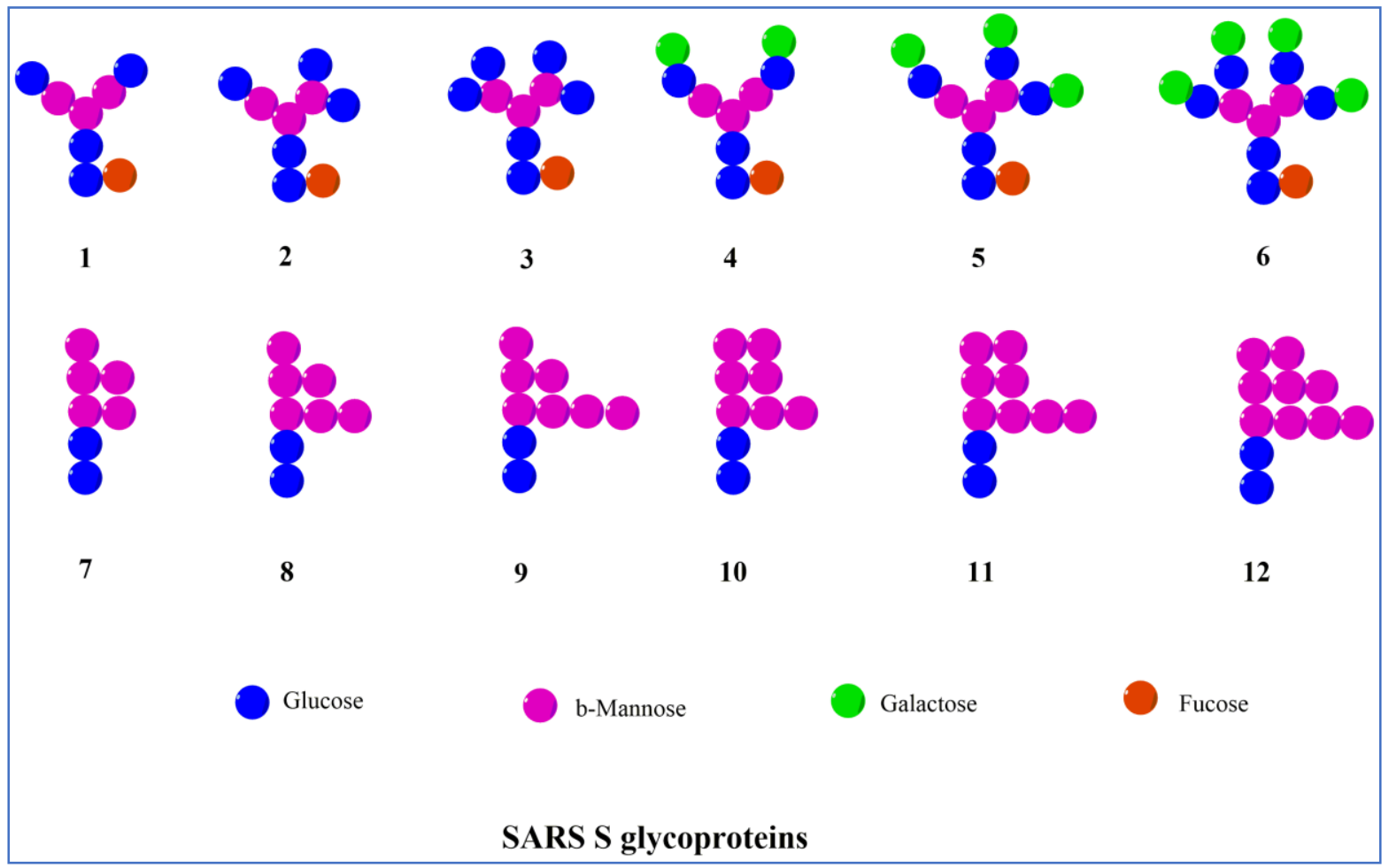

Fig. 1S Structure of S glycoprotein of SARS-CoV-1; Drawn by ChemDraw professional

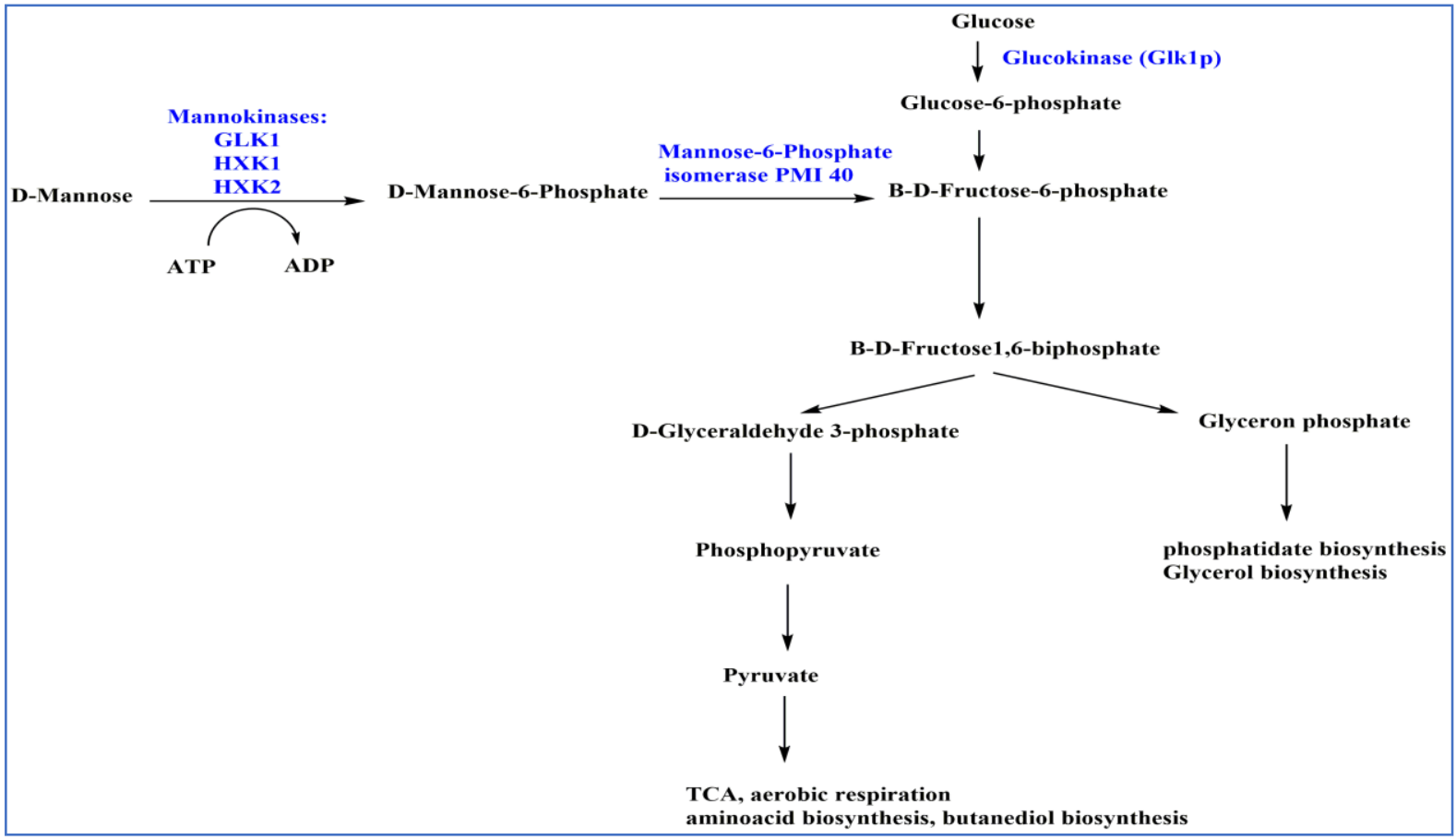

Fig. 2S Glycolysis of sugars in Saccharomyces cerevisiae; Drawn by ChemDraw professional 


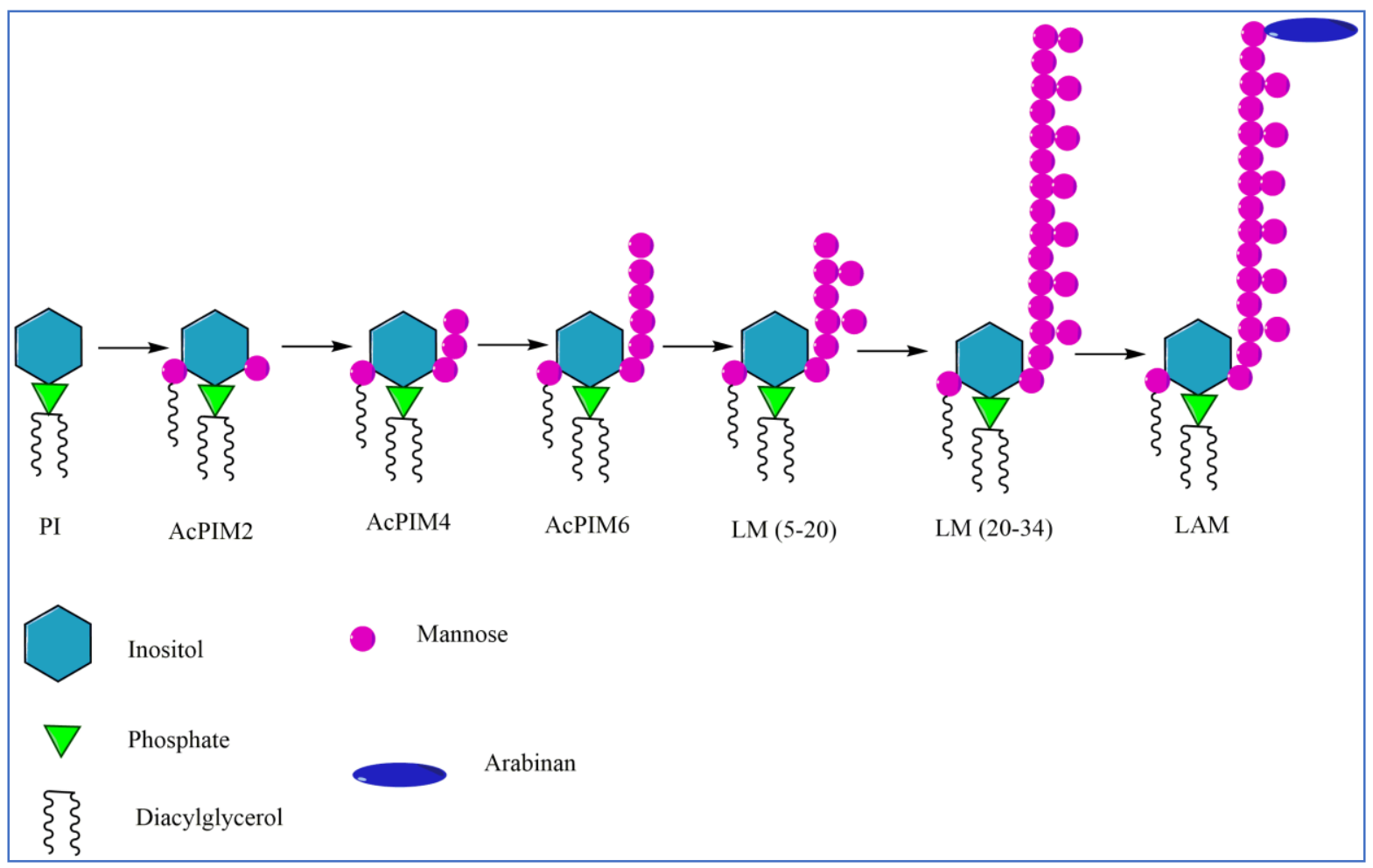

Fig. 3S Glycan structure of Mycobacterium avium; Drawn by ChemDraw professional

PI: Phospho-inositol, PIM: Phosphatidylinositol mannosides, LM: lipomannan, and LAM: lipoarabinomannan

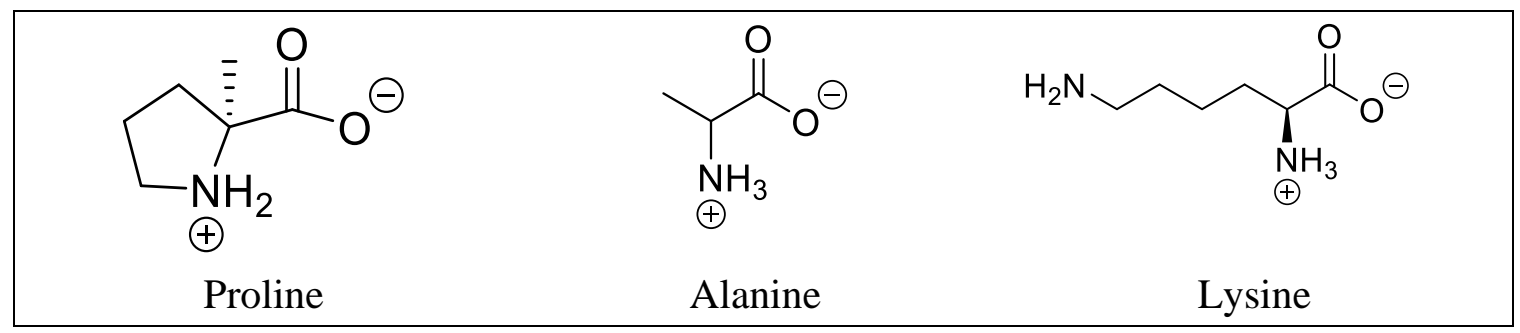

Fig. 4S Structure of amino acids in C-terminus of HBHA of M. Avium; Drawn by ChemDraw professional 


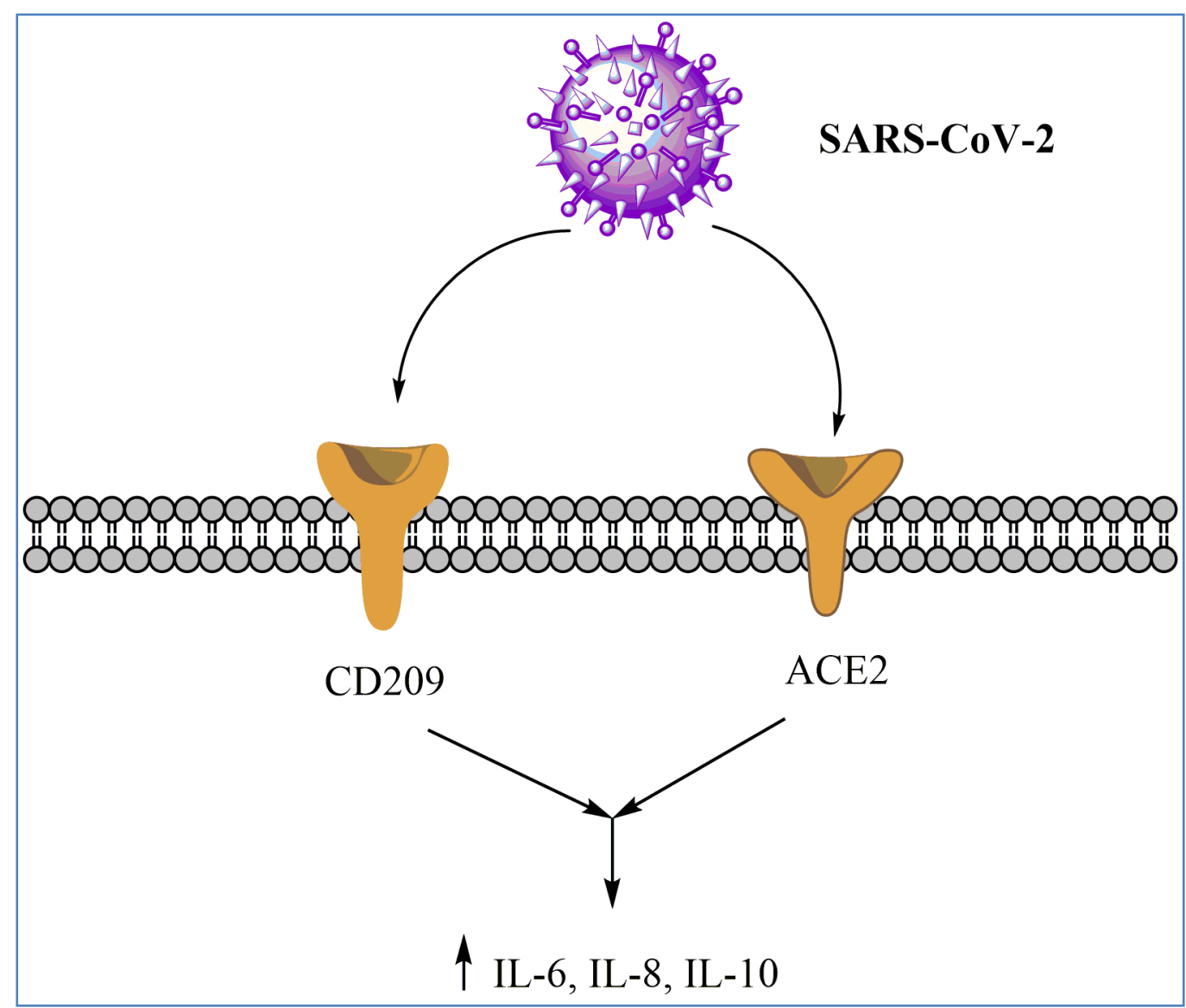

Fig. 5S SARS-CoV-2 host cell interaction; Drawn by ChemDraw professional 


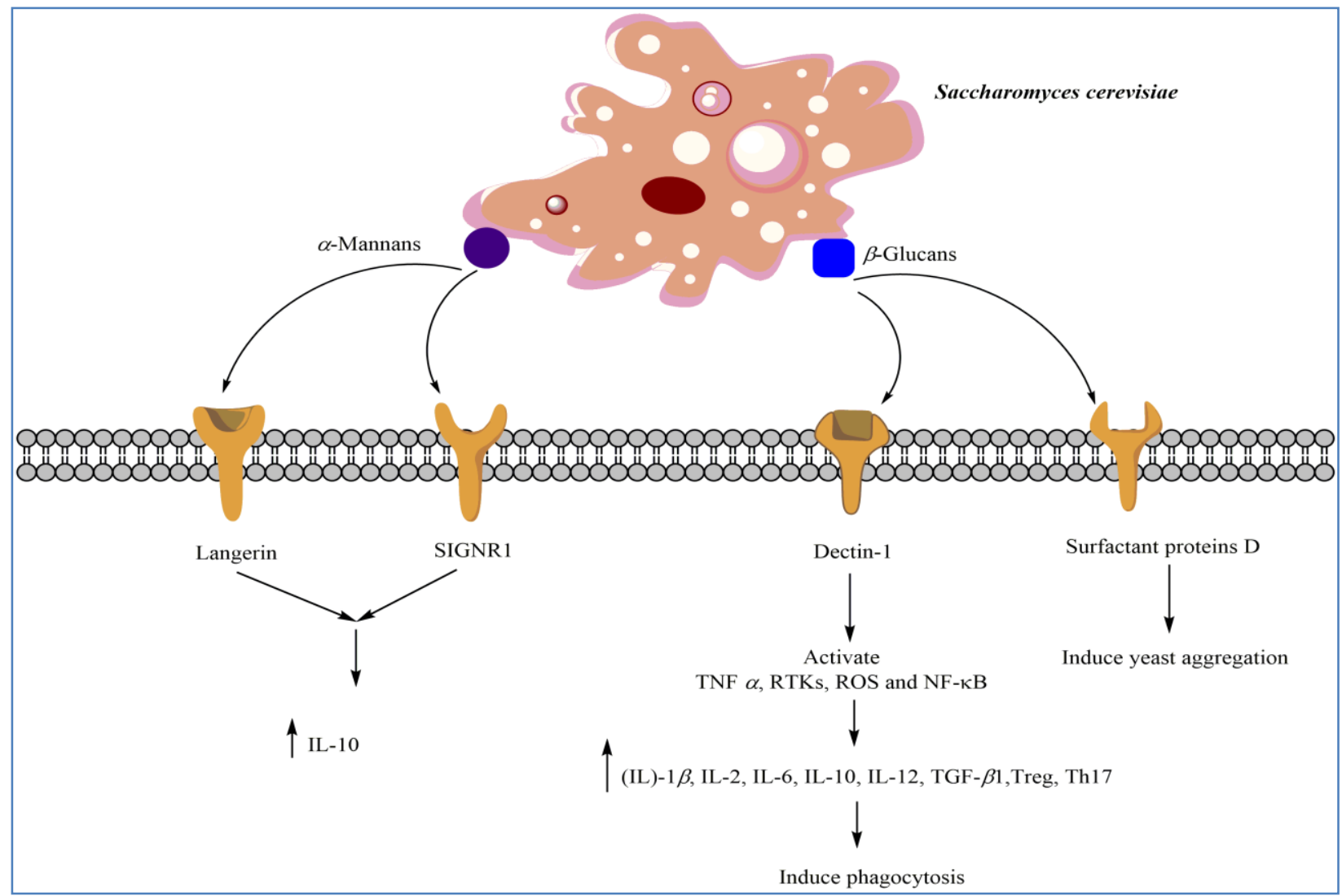

Fig. 6S Saccharomyces cerevisiae host cell interaction; Drawn by ChemDraw professional 


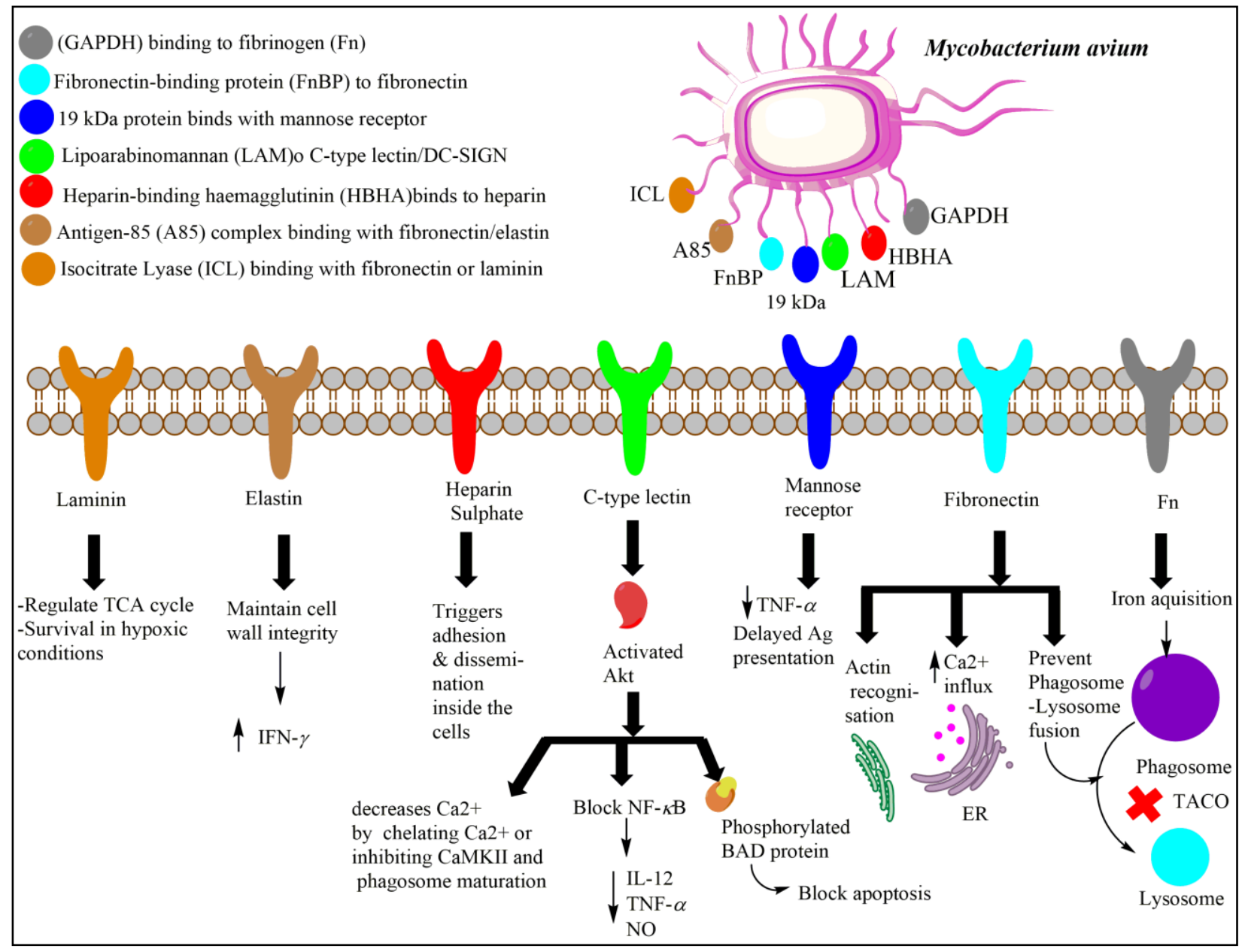

Fig. 7S Mycobacterium avium host cell interaction; Drawn by ChemDraw professional

- Heparin-binding haemagglutinin binds to sulphated surface receptors such as heparine sulphate present on host cell and triggers mycobacterial dissemination which is important for its survival inside the host cell [204].

- Binding of lipoarabinomannan to CD209, a C-type lectin, stimulates Akt protein which phosphorylates Bad protein, and hence, the intrinsic apoptotic pathway is blocked [205].

- Glyceraldehyde 3-phosphate dehydrogenase (GAPDH) binding to fibrinogen (Fn) on the host cell induces the uptake of iron which is to be acquired by the host cell for its own use [148].

- Adhesion of fibronectin-binding protein (FnBP) to fibronectin stimulates FAK/Src kinase which also leads to actin reorganization and also recruits tryptophan aspartate containing coat protein to early phagosome and prevents its fusion with lysosome. It also triggers calcium upregulation [206].

- Isocitrate Lyase binding with fibronectin or laminin has been shown. It mainly helps bacteria to survive under hypoxic conditions inside the host cell [207] .

- Antigen-85 complex (85B and MPT51) binding with fibronectin/elastin induces interferon- $\gamma$ (IFN- $\gamma$ ) which indicates that it also participates in host cell signalling mechanism [208].

- $19 \mathrm{kDa}$ protein (maltose-binding protein) binds with mannose receptor and blocks human leukocyte antigen-antigen D-related (HLA-DR) protein present on major histocompatibility complex II (MHC-II) and leads to delayed antigen presentation [209]. 


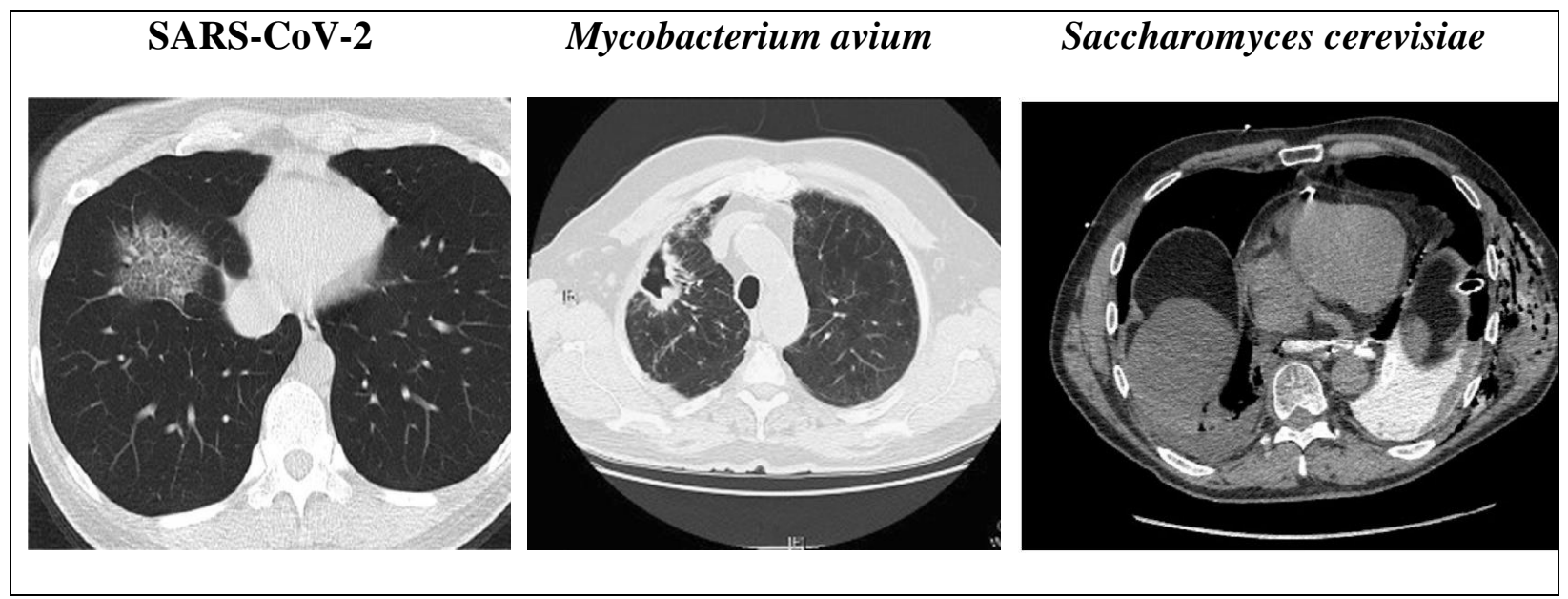

Fig. 8S Lung CT scan examination

MARRARVDAELVRRGLARSRQQAAELIGAGKVRIDGLPAVKPATAVSDTTALTVVTDSER AWVSRGAHKLVGALEAFAIAVAGRRCLDAGASTGGFTEVLLDRGAAHVVAADVGYGQLAW SLRNDPRVVVLERTNARGLTPEAIGGRVDLVVADLSFISLATVLPALVGCASRDADIVPL VKPQFEVGKGQVGPGGVVHDPQLRARSVLAVARRAQELGWHSVGVKASPLPGPSGNVEYF LWLRTQTDRALSAKGLEDAVHRAISEGP

Fig. 9S Amino acid sequence of 16S/23S rRNA (cytidine-2'-O)-methyltransferase (TlyA) 


\section{References}

1. Li Q, Guan X, Wu P, Wang X, Zhou L, Tong Y, Ren R, Leung KS, Lau EH, Wong JY: Early transmission dynamics in Wuhan, China, of novel coronavirus-infected pneumonia. New England Journal of Medicine 2020.

2. Zhou P, Yang X-L, Wang X-G, Hu B, Zhang L, Zhang W, Si H-R, Zhu Y, Li B, Huang CL: A pneumonia outbreak associated with a new coronavirus of probable bat origin. nature 2020, 579(7798):270-273.

3. WHO: SITUATION REPORT-5 25 JANUARY 2020. World Health 2019, 251.

4. Gorbalenya AE: Severe acute respiratory syndrome-related coronavirus-The species and its viruses, a statement of the Coronavirus Study Group. BioRxiv 2020.

5. $\quad \mathrm{Wu}$ Y, Ho W, Huang Y, Jin D-Y, Li S, Liu S-L, Liu X, Qiu J, Sang Y, Wang Q: SARSCoV-2 is an appropriate name for the new coronavirus. The Lancet 2020, 395(10228):949-950.

6. Zhang Y: Novel 2019 coronavirus genome. Virological[Accessed 21 Jan 2020] 2020.

7. Dong N, Yang X, Ye L, Chen K, Chan EW-C, Yang M, Chen S: Genomic and protein structure modelling analysis depicts the origin and infectivity of 2019-nCoV, a new coronavirus which caused a pneumonia outbreak in Wuhan, China. bioRxiv 2020.

8. Lam TT-Y, Shum MH-H, Zhu H-C, Tong Y-G, Ni X-B, Liao Y-S, Wei W, Cheung WY$\mathrm{M}$, Li W-J, Li L-F: Identification of 2019-nCoV related coronaviruses in Malayan pangolins in southern China. BioRxiv 2020.

9. Stegeman A, Bouma A, Elbers AR, de Jong MC, Nodelijk G, de Klerk F, Koch G, van Boven M: Avian influenza A virus (H7N7) epidemic in The Netherlands in 2003: course of the epidemic and effectiveness of control measures. The Journal of Infectious Diseases 2004, 190(12):2088-2095.

10. Yu H, Wu JT, Cowling BJ, Liao Q, Fang VJ, Zhou S, Wu P, Zhou H, Lau EH, Guo D: Effect of closure of live poultry markets on poultry-to-person transmission of avian influenza A H7N9 virus: an ecological study. The Lancet 2014, 383(9916):541-548.

11. Salazar N, de los Reyes-Gavilán CG: Insights into microbe-microbe interactions in human microbial ecosystems: strategies to be competitive. Frontiers in microbiology 2016, 7:1508.

12. Boni MF, Lemey P, Jiang X, Lam TT-Y, Perry B, Castoe T, Rambaut A, Robertson DL: Evolutionary origins of the SARS-CoV-2 sarbecovirus lineage responsible for the COVID-19 pandemic. bioRxiv 2020.

13. Patino-Galindo JA, Filip I, AlQuraishi M, Rabadan R: Recombination and lineagespecific mutations led to the emergence of SARS-CoV-2. bioRxiv 2020.

14. Nielsen J: Production of biopharmaceutical proteins by yeast: advances through metabolic engineering. Bioengineered 2013, 4(4):207-211.

15. Liu R-S, Yang K-Y, Lin J, Lin Y-W, Zhang Z-H, Zhang J, Xia N-S: High-yield expression of recombinant SARS coronavirus nucleocapsid protein in methylotrophic yeast Pichia pastoris. World J Gastroenterol 2004, 10(24):3602-3607.

16. Thao TTN, Labroussaa F, Ebert N, V'kovski P, Stalder H, Portmann J, Kelly J, Steiner S, Holwerda M, Kratzel A: Rapid reconstruction of SARS-CoV-2 using a synthetic genomics platform. bioRxiv 2020.

17. Hua L, Gong S, Wang F, Li W, Ge Y, Li X, Hou F: Captive breeding of pangolins: current status, problems and future prospects. ZooKeys 2015(507):99. 
18. Challender DW, Nash HC, Waterman C: Pangolins: Science, Society and Conservation: Academic Press; 2019.

19. Nature: Chinese Medicine and the Pangolin. Nature 1938, 141(3558):72-72.

20. Pangolins [https://www.journalofchinesemedicine.com/news/pangolin-use-in-traditionalmedicine/]

21. Li S: A medicine for treating lymphatic tuberculosis and preparation method thereof [Machine Translation]. In.: Shanxian Chunmin Banlangen Planting Cooperative, Peop. Rep. China . 2019.

22. Mu L: A traditional chinese medicinal composition for treating lymphatic tuberculosis and lymphoma [Machine Translation]. In.: Shandong Fengmingtang Pharmaceutical Technology Co., Ltd., Peop. Rep. China . 2015.

23. Liu S: Sanjie pill for treating tumor and preparation method thereof [Machine Translation]. In.: Peop. Rep. China . 2019.

24. Chen $\mathrm{G}$, Chang B, Chen $\mathrm{H}$ : A powder for treating mammary tuberculosis in pus stage [Machine Translation]. In.: Peop. Rep. China . 2016.

25. Chen $\mathrm{G}$, Wang $\mathrm{F}$, Chen $\mathrm{H}$ : An external application aqua for treating mammary tuberculosis at pus period [Machine Translation]. In.: Peop. Rep. China . 2016.

26. Sun S: A medicine composition for treating tuberculosis in bone and joint. In.: Peop. Rep. China . 2016: 6pp.

27. Wang F, Chen $\mathrm{T}$ : Traditional Chinese medicine preparation for treating joint tuberculosis. In.: Peop. Rep. China . 2016: 8pp.

28. Tang Y: A traditional chinese medicinal composition for the treatment of bronchial tuberculosis [Machine Translation]. In.: Peop. Rep. China . 2015.

29. Hou Z: A kind of traditional Chinese medicine composition for treatment of lung disease. In.: Peop. Rep. China . 2015: 9pp.

30. Yang CW, Chen S, Chang CY, Lin MF, Block E, Lorentsen R, Chin JS, Dierenfeld ES: History and dietary husbandry of pangolins in captivity. Zoo Biology: Published in affiliation with the American Zoo and Aquarium Association 2007, 26(3):223-230.

31. PANTEL EBS, CHIN S: WORKSHOP ON TRADE AND CONSERVATION OF PANGOLINS NATIVE TO SOUTH AND SOUTHEAST ASIA. 2009.

32. Lihua C, Liang X, Hui X, Yunya X, Zhongfeng X: Protection and Cultivated Technology of Pangolin. Asia-Pacific Traditional Medicine 2010, 2(006).

33. Chang C: Study on the apparent digestibility of diet on Formosan pangolin. National Taiwan University, Taipei, Taiwan[In Chinese] 2004.

34. Aucott JN, Fayen J, Grossnicklas H, Morrissey A, Lederman MM, Salata RA: Invasive infection with Saccharomyces cerevisiae: report of three cases and review. Clinical Infectious Diseases 1990, 12(3):406-411.

35. Doyle M, Pickering LK, O'Brien N, Hoots K: Saccharomyces cerevisiae infection in a patient with acquired immunodeficiency syndrome. Pediatric Infectious Disease Journal 1990, 9(11):850-851.

36. Munoz P, Bouza E, Cuenca-Estrella M, Eiros JM, Pérez MJ, Sánchez-Somolinos M, Rincón C, Hortal J, Peláez T: Saccharomyces cerevisiae fungemia: an emerging infectious disease. Clinical Infectious Diseases 2005, 40(11):1625-1634.

37. Liu P, Chen W, Chen J-P: Viral Metagenomics Revealed Sendai Virus and Coronavirus Infection of Malayan Pangolins (Manis javanica). Viruses 2019, 11(11):979. 
38. Sharma V, Hecker N, Walther F, Stuckas H, Hiller M: Convergent losses of TLR5 suggest altered extracellular flagellin detection in four mammalian lineages. Molecular Biology and Evolution 2020.

39. Watanabe Y, Berndsen ZT, Raghwani J, Seabright GE, Allen JD, McLellan JS, Wilson IA, Bowden TA, Ward AB, Crispin M: Vulnerabilities in coronavirus glycan shields despite extensive glycosylation. BioRxiv 2020.

40. Zhou D, Qi R, Zhang W, Tian X, Peng C: Identification of 22 N-glycosites on Spike Glycoprotein of SARS-CoV-2 and Accessible Surface Glycopeptide Motifs: Implications on Vaccination and Antibody Therapeutics. 2020.

41. Uslupehlivan M, Şener E: Glycoinformatics approach for identifying target positions to inhibit initial binding of SARS-CoV-2 S1 protein to the host cell. bioRxiv 2020:2020.2003.2025.007898.

42. Lu R, Zhao X, Li J, Niu P, Yang B, Wu H, Wang W, Song H, Huang B, Zhu N: Genomic characterisation and epidemiology of 2019 novel coronavirus: implications for virus origins and receptor binding. The Lancet 2020, 395(10224):565-574.

43. Letko MC, Munster V: Functional assessment of cell entry and receptor usage for lineage B $\beta$-coronaviruses, including 2019-nCoV. bioRxiv 2020.

44. Andersen KG, Rambaut A, Lipkin WI, Holmes EC, Garry RF: The proximal origin of SARS-CoV-2. Nature medicine 2020, 26(4):450-452.

45. Zhang T, Wu Q, Zhang Z: Probable pangolin origin of SARS-CoV-2 associated with the COVID-19 outbreak. Current Biology 2020.

46. Maaroufi H: The Spike Protein S1 Subunit of SARS-CoV-2 Contains an LxxIxE-like Motif that is Known to Recruit the Host PP2A-B56 Phosphatase. bioRxiv 2020:2020.2004.2001.020941.

47. Fraenkel DG: The top genes: on the distance from transcript to function in yeast glycolysis. Current opinion in microbiology 2003, 6(2):198-201.

48. Strathern JN, Jones EW, Broach JR: Molecular biology of the yeast Saccharomyces: Cold Spring Harbor Laboratory; 1982.

49. Schüller H-J: Transcriptional control of nonfermentative metabolism in the yeast Saccharomyces cerevisiae. Current genetics 2003, 43(3):139-160.

50. Lobo Z, Maitra P: Genetics of yeast hexokinase. Genetics 1977, 86(4):727-744.

51. Özcan S, Johnston M: Function and regulation of yeast hexose transporters. Microbiol Mol Biol Rev 1999, 63(3):554-569.

52. O'Donnell AF, Schmidt MC: AMPK-mediated regulation of alpha-arrestins and protein trafficking. International journal of molecular sciences 2019, 20(3):515.

53. Herrero P, Galindez J, Ruiz N, Martinez-Campa C, Moreno F: Transcriptional regulation of the Saccharomyces cerevisiae HXK1, HXK2 and GLK1 genes. Yeast 1995, 11(2):137-144.

54. Hardie DG, Carling D, Carlson M: The AMP-activated/SNF1 protein kinase subfamily: metabolic sensors of the eukaryotic cell? In.: Annual Reviews 4139 El Camino Way, PO Box 10139, Palo Alto, CA 94303-0139, USA; 1998.

55. Brinkworth RI, Munn AL, Kobe B: Protein kinases associated with the yeast phosphoproteome. BMC bioinformatics 2006, 7(1):47.

56. Gemmill TR, Trimble RB: Overview of $\mathbf{N}$-and $\mathbf{O}$-linked oligosaccharide structures found in various yeast species. Biochimica et Biophysica Acta (BBA)-General Subjects 1999, 1426(2):227-237. 
57. Jigami Y: Yeast glycobiology and its application. Bioscience, biotechnology, and biochemistry 2008, 72(3):637-648.

58. Nakanishi-Shindo Y, Nakayama K-I, Tanaka A, Toda Y, Jigami Y: Structure of the Nlinked oligosaccharides that show the complete loss of alpha-1, 6-polymannose outer chain from och1, och1 mnn1, and och1 mnn1 alg3 mutants of Saccharomyces cerevisiae. Journal of Biological Chemistry 1993, 268(35):26338-26345.

59. Stertz S, Reichelt M, Spiegel M, Kuri T, Martínez-Sobrido L, García-Sastre A, Weber F, Kochs G: The intracellular sites of early replication and budding of SARScoronavirus. Virology 2007, 361(2):304-315.

60. Fehr AR, Perlman S: Coronaviruses: an overview of their replication and pathogenesis. In: Coronaviruses. Springer; 2015: 1-23.

61. Ng M-L, Tan S-H, See E-E, Ooi E-E, Ling A-E: Proliferative growth of SARS coronavirus in Vero E6 cells. Journal of General Virology 2003, 84(12):3291-3303.

62. Ritchie G, Harvey DJ, Feldmann F, Stroeher U, Feldmann H, Royle L, Dwek RA, Rudd PM: Identification of $\mathrm{N}$-linked carbohydrates from severe acute respiratory syndrome (SARS) spike glycoprotein. Virology 2010, 399(2):257-269.

63. Walls AC, Xiong X, Park Y-J, Tortorici MA, Snijder J, Quispe J, Cameroni E, Gopal R, Dai M, Lanzavecchia A: Unexpected receptor functional mimicry elucidates activation of coronavirus fusion. Cell 2019, 176(5):1026-1039. e1015.

64. Thak EJ, Kim J, Lee D-J, Kim JY, Kang HA: Structural analysis of N-/O-glycans assembled on proteins in yeasts. journal of microbiology 2018, 56(1):11-23.

65. Carter G, Wu M, Drummond DC, Bermudez LE: Characterization of biofilm formation by clinical isolates of Mycobacterium avium. Journal of medical microbiology 2003, 52(9):747-752.

66. Prince DS, Peterson DD, Steiner RM, Gottlieb JE, Scott R, Israel HL, Figueroa WG, Fish JE: Infection with Mycobacterium avium complex in patients without predisposing conditions. New England Journal of Medicine 1989, 321(13):863-868.

67. Diel R, Lipman M, Hoefsloot W: High mortality in patients with Mycobacterium avium complex lung disease: a systematic review. BMC infectious diseases 2018, 18(1):206.

68. Van der Werf MJ, Ködmön C, Katalinić-Janković V, Kummik T, Soini H, Richter E, Papaventsis D, Tortoli E, Perrin M, van Soolingen D: Inventory study of nontuberculous mycobacteria in the European Union. BMC infectious diseases 2014, 14(1):62.

69. Faria S, Joao I, Jordao L: General overview on nontuberculous mycobacteria, biofilms, and human infection. Journal of pathogens 2015, 2015.

70. Coelho AC, de Lurdes Pinto M, Matos A, Matos M, dos Anjos Pires M: Mycobacterium avium complex in domestic and wild animals. In: Insights from veterinary medicine. IntechOpen; 2013.

71. Lescenko P, Matlova L, Dvorska L, Bartos M, Vavra O, Navratil S, Novotny L, Pavlik I: Mycobacterial infection in aquarium fish. Veterinarni Medicina 2003, 48(3):71-78.

72. Yamazaki Y, Danelishvili L, Wu M, MacNab M, Bermudez LE: Mycobacterium avium Genes Associated with the Ability To Form a Biofilm. Applied and Environmental Microbiology 2006, 72(1):819-825.

73. Rose SJ, Babrak LM, Bermudez LE: Mycobacterium avium Possesses Extracellular DNA that Contributes to Biofilm Formation, Structural Integrity, and Tolerance to Antibiotics. PLoS One 2015, 10(5):e0128772-e0128772. 
74. Chakraborty P, Kumar A: The extracellular matrix of mycobacterial biofilms: could we shorten the treatment of mycobacterial infections? Microbial Cell 2019, 6(2):105.

75. Karatan E, Watnick P: Signals, regulatory networks, and materials that build and break bacterial biofilms. Microbiol Mol Biol Rev 2009, 73(2):310-347.

76. Vadyvaloo V, Martínez L: Mechanisms of post-transcriptional gene regulation in bacterial biofilms. Frontiers in cellular and infection microbiology 2014, 4:38.

77. Aparna MS, Yadav S: Biofilms: microbes and disease. Brazilian Journal of Infectious Diseases 2008, 12(6):526-530.

78. Holst O, Moran AP, Brennan PJ: Chapter 1 - Overview of the glycosylated components of the bacterial cell envelope. In: Microbial Glycobiology. Edited by Holst O, Brennan PJ, Itzstein Mv, Moran AP. San Diego: Academic Press; 2010: 1-13.

79. Chiacchio T, Delogu G, Vanini V, Cuzzi G, De Maio F, Pinnetti C, Sampaolesi A, Antinori A, Goletti D: Immune characterization of the HBHA-specific response in Mycobacterium tuberculosis-infected patients with or without HIV infection. PLoS One 2017, 12(8).

80. Raze D, Verwaerde C, Deloison G, Werkmeister E, Coupin B, Loyens M, Brodin P, Rouanet C, Locht C: Heparin-binding Hemagglutinin Adhesin (HBHA) is involved in intracytosolic lipid inclusions formation in mycobacteria. Frontiers in microbiology 2018, 9:2258.

81. Squeglia F, Ruggiero A, De Simone A, Berisio R: A structural overview of mycobacterial adhesins: Key biomarkers for diagnostics and therapeutics. Protein Science 2018, 27(2):369-380.

82. Pethe K, Bifani P, Drobecq H, Sergheraert C, Debrie A-S, Locht C, Menozzi FD: Mycobacterial heparin-binding hemagglutinin and laminin-binding protein share antigenic methyllysines that confer resistance to proteolysis. Proceedings of the National Academy of Sciences 2002, 99(16):10759-10764.

83. Esposito C, Carullo P, Pedone E, Graziano G, Del Vecchio P, Berisio R: Dimerisation and structural integrity of Heparin Binding Hemagglutinin A from Mycobacterium tuberculosis: Implications for bacterial agglutination. FEBS letters 2010, 584(6):10911096.

84. Henzi V, Reichling DB, Helm SW, MacDermott A: L-proline activates glutamate and glycine receptors in cultured rat dorsal horn neurons. Molecular pharmacology 1992, 41(4):793-801.

85. Arslan OE: Neuroanatomical basis of clinical neurology: CRC Press; 2014.

86. Zondlo NJ: Aromatic-proline interactions: electronically tunable $\mathbf{C H} / \boldsymbol{\pi}$ interactions. Accounts of chemical research 2013, 46(4):1039-1049.

87. Morris AL, MacArthur MW, Hutchinson EG, Thornton JM: Stereochemical quality of protein structure coordinates. Proteins: Structure, Function, and Bioinformatics 1992, 12(4):345-364.

88. Harriff MJ, Danelishvili L, Wu M, Wilder C, McNamara M, Kent ML, Bermudez LE: Mycobacterium avium genes MAV_5138 and MAV_3679 are transcriptional regulators that play a role in invasion of epithelial cells, in part by their regulation of CipA, a putative surface protein interacting with host cell signaling pathways. $J$ Bacteriol 2009, 191(4):1132-1142.

89. Mirey G, Soulard A, Orange C, Friant S, Winsor B: SH3 domain-containing proteins and the actin cytoskeleton in yeast. Biochem Soc Trans 2005, 33(Pt 6):1247-1249. 
90. Via A, Uyar B, Brun C, Zanzoni A: How pathogens use linear motifs to perturb host cell networks. Trends in Biochemical Sciences 2015, 40(1):36-48.

91. Lee C-H, Leung B, Lemmon M, Zheng J, Cowburn D, Kuriyan J, Saksela K: A single amino acid in the SH3 domain of Hck determines its high affinity and specificity in binding to HIV-1 Nef protein. The EMBO journal 1995, 14(20):5006-5015.

92. Shelton H, Harris M: Hepatitis C virus NS5A protein binds the SH3 domain of the Fyn tyrosine kinase with high affinity: mutagenic analysis of residues within the SH3 domain that contribute to the interaction. Virology Journal 2008, 5(1):24.

93. Menozzi FD, Bischoff R, Fort E, Brennan MJ, Locht C: Molecular characterization of the mycobacterial heparin-binding hemagglutinin, a mycobacterial adhesin. Proceedings of the National Academy of Sciences 1998, 95(21):12625-12630.

94. Pethe K, Alonso S, Biet F, Delogu G, Brennan MJ, Locht C, Menozzi FD: The heparinbinding haemagglutinin of $M$. tuberculosis is required for extrapulmonary dissemination. Nature 2001, 412(6843):190-194.

95. Biasini M, Bienert S, Waterhouse A, Arnold K, Studer G, Schmidt T, Kiefer F, Cassarino TG, Bertoni M, Bordoli L: SWISS-MODEL: modelling protein tertiary and quaternary structure using evolutionary information. Nucleic acids research 2014, 42(W1):W252-W258.

96. Eriksson O: Dynamics of genets in clonal plants. Trends in Ecology \& Evolution 1993, 8(9):313-316.

97. Ojanen MJ, Turpeinen H, Cordova ZM, Hammarén MM, Harjula S-KE, Parikka M, Rämet M, Pesu M: The proprotein convertase subtilisin/kexin furinA regulates zebrafish host response against Mycobacterium marinum. Infection and immunity 2015, 83(4):14311442.

98. Artenstein AW, Opal SM: Proprotein convertases in health and disease. New England Journal of Medicine 2011, 365(26):2507-2518.

99. NCBI: FURIN furin, paired basic amino acid cleaving enzyme [ Manis javanica (Malayan pangolin) ]. In.; 2017.

100. Hoefsloot W, Van Ingen J, Andrejak C, Ängeby K, Bauriaud R, Bemer P, Beylis N, Boeree MJ, Cacho J, Chihota V: The geographic diversity of nontuberculous mycobacteria isolated from pulmonary samples: an NTM-NET collaborative study. European Respiratory Journal 2013, 42(6):1604-1613.

101. Simons S, Van Ingen J, Hsueh P-R, Van Hung N, Dekhuijzen PR, Boeree MJ, Van Soolingen D: Nontuberculous mycobacteria in respiratory tract infections, eastern Asia. Emerging infectious diseases 2011, 17(3):343.

102. Niemirowska H, Chrostowski K, Krakówka P, Styszewska H, Kucharska I, PecynaSielewicz J: Course of pulmonary tuberculosis in patients with different degree of lactose and milk tolerance. Pneumonologia polska 1980, 48(1):16-22.

103. Allison Thorn F-B: Understanding Lactose Intolerance. CLINICAL REVIEW 2010, 20(11).

104. Di Stefano GVSMASGRCM: Lactose Malabsorption and Intolerance in the Elderly. Scandinavian Journal of Gastroenterology 2001, 36(12):1274-1278.

105. Wang D, Hu B, Hu C, Zhu F, Liu X, Zhang J, Wang B, Xiang H, Cheng Z, Xiong Y et al: Clinical Characteristics of 138 Hospitalized Patients With 2019 Novel CoronavirusInfected Pneumonia in Wuhan, China. JAMA 2020, 323(11):1061-1069.

106. Organization WH: Coronavirus disease 2019 (COVID-19): situation report, 70. 2020. 
107. Bolin T, Crane G, Davis A: Lactose intolerance in various ethnic groups in South-East Asia. Australasian annals of medicine 1968, 17(4):300-306.

108. Yang Y, He M, Cui H, Bian L, Wang Z: The prevalence of lactase deficiency and lactose intolerance in Chinese children of different ages. Chinese medical journal 2000, 113(12):1129-1132.

109. Bayless TM, Brown E, Paige DM: Lactase non-persistence and lactose intolerance. Current gastroenterology reports 2017, 19(5):23.

110. Bozanni A, Penagini R, Velio P, Camboni G, Corbelli A, Quatrini M: Lactose malabsorption and intolerance in Italians. Dig Dis Sci 1986, 31:1313-1316.

111. Cavalli-Sforza LT, Strata A, Barone A, Cucurachi L: Primary adult lactose malabsorption in Italy: regional differences in prevalence and relationship to lactose intolerance and milk consumption. The American journal of clinical nutrition 1987, 45(4):748-754.

112. Lactose-Free Continues to Grow in Spain [https://www.bordbia.ie/industry/insights/food-alert/lactose-free-continues-to-grow-inspain/]

113. Zhao J, Yang Y, Huang H, Li D, Gu D, Lu X, Zhang Z, Liu L, Liu T, Liu Y et al: Relationship between the ABO Blood Group and the COVID-19 Susceptibility. medRxiv 2020:2020.2003.2011.20031096.

114. Lau FH, Majumder R, Torabi R, Saeg F, Hoffman R, Cirillo JD, Greiffenstein P: Vitamin $\mathrm{D}$ Insufficiency is Prevalent in Severe COVID-19. medRxiv 2020:2020.2004.2024.20075838.

115. Alharbi O, El-Sohemy A: Lactose intolerance (LCT-13910C> T) genotype is associated with plasma 25-hydroxyvitamin $D$ concentrations in Caucasians: a Mendelian randomization study. The Journal of nutrition 2017, 147(6):1063-1069.

116. D'Adamo P, Whitney C: Eat Right for Your Type: The Individualized Blood Type Diet Solution: Penguin; 2016.

117. Heck S, Bender K, Kullmann M, Göttlicher M, Herrlich P, Cato AC: IкB $\boldsymbol{\alpha}$-independent downregulation of $\mathbf{N F}-\kappa \mathbf{B}$ activity by glucocorticoid receptor. The EMBO Journal 1997, 16(15):4698-4707.

118. Cullen PJ: Biofilm/mat assays for budding yeast. Cold Spring Harbor Protocols 2015, 2015(2):pdb. prot085076.

119. Thoulouze M-I, Alcover A: Can viruses form biofilms? Trends in microbiology 2011, 19(6):257-262.

120. van Doremalen N, Bushmaker T, Morris DH, Holbrook MG, Gamble A, Williamson BN, Tamin A, Harcourt JL, Thornburg NJ, Gerber SI: Aerosol and surface stability of SARSCoV-2 as compared with SARS-CoV-1. New England Journal of Medicine 2020, 382(16):1564-1567.

121. Naddeo V, Liu H: Editorial Perspectives: 2019 novel coronavirus (SARS-CoV-2): what is its fate in urban water cycle and how can the water research community respond? Environmental Science: Water Research \& Technology 2020.

122. Gautret P, Lagier J-C, Parola P, Hoang VT, Meddeb L, Mailhe M, Doudier B, Courjon J, Giordanengo V, Vieira VE et al: Hydroxychloroquine and azithromycin as a treatment of COVID-19: results of an open-label non-randomized clinical trial. Int J Antimicrob Agents 2020:105949-105949. 
123. Favre-Bonté $\mathrm{S}$, Köhler $\mathrm{T}$, Van Delden $\mathrm{C}$ : Biofilm formation by Pseudomonas aeruginosa: role of the C4-HSL cell-to-cell signal and inhibition by azithromycin. Journal of antimicrobial chemotherapy 2003, 52(4):598-604.

124. Li X-H, Lee J-H: Antibiofilm agents: A new perspective for antimicrobial strategy. Journal of Microbiology 2017, 55(10):753-766.

125. Millet JK, Whittaker GR: Host cell entry of Middle East respiratory syndrome coronavirus after two-step, furin-mediated activation of the spike protein. Proc Natl Acad Sci U S A 2014, 111(42):15214-15219.

126. Mamo G, Bayleyegn G, Tessema TS, Legesse M, Medhin G, Bjune G, Abebe F, Ameni G: Pathology of camel tuberculosis and molecular characterization of its causative agents in pastoral regions of Ethiopia. PLoS One 2011, 6(1).

127. Kinne J, Johnson B, Jahans K, Smith N, Ul-Haq A, Wernery U: Camel tuberculosis-a case report. Tropical animal health and production 2006, 38(3):207-213.

128. Ahmed ET-AET, Hassan AB, Abakar AD: Pathology of Tuberculosis in Camels (Camelus dromedaries) in the Sudan. Journal of Tuberculosis Research 2017, 5(1):7780 .

129. Lecrubier A: Children With Kawasaki-Like Disease Positive for COVID-19. In. Medscape Medical News: Medscape Medical News; 2020.

130. Atıcı S, Soysal A, Cerit KK, Yılmaz Ş, Aksu B, Kıyan G, Bakır M: Catheter-related Saccharomyces cerevisiae Fungemia Following Saccharomyces boulardii Probiotic Treatment: In a child in intensive care unit and review of the literature. Medical mycology case reports 2017, 15:33-35.

131. Gkentzi D, Marangos M, Karatza A, Spiliopoulou A, Varvarigou A, Dimitriou G: SACCHAROMYCES CEREVISIAE FUNGAEMIA IN AN IMMUNOCOMPETENT TODDLER. Journal of Paediatrics and Child Health 2020, 56(1):182-182.

132. Chakravarty S, Parashar A, Acharyya S: Saccharomyces cerevisiae Sepsis Following Probiotic Therapy in an Infant. Indian pediatrics 2019, 56(11):971-972.

133. Romanio MR, Coraine LA, Maielo VP, Abramczyc ML, Souza RLd, Oliveira NF: SACCHAROMYCES CEREVISIAE FUNGEMIA IN A PEDIATRIC PATIENT AFTER TREATMENT WITH PROBIOTICS. Rev Paul Pediatr 2017, 35(3):361-364.

134. Fiore NF, Conway JH, West KW, Kleiman MB: Saccharomyces cerevisiae infections in children. The Pediatric infectious disease journal 1998, 17(12):1177-1179.

135. Eisenman HC, Casadevall A: Synthesis and assembly of fungal melanin. Applied microbiology and biotechnology 2012, 93(3):931-940.

136. Roy P, Nayak KK, Pandey NK: Characterization of a novel yeast synthesizing melaninlike pigment. Microbiology 1989, 135(12):3385-3391.

137. Walker CA, Gómez BL, Mora-Montes HM, Mackenzie KS, Munro CA, Brown AJP, Gow NAR, Kibbler CC, Odds FC: Melanin externalization in Candida albicans depends on cell wall chitin structures. Eukaryot Cell 2010, 9(9):1329-1342.

138. Goodman B: Blood Clots Are Another Dangerous COVID-19 Mystery. In.: WebMD; 2020.

139. Willyard C: Coronavirus blood-clot mystery intensifies. In. Nature: Nature; 2020.

140. Klok FA, Kruip M, Van der Meer N, Arbous M, Gommers D, Kant K, Kaptein F, van Paassen J, Stals M, Huisman M: Confirmation of the high cumulative incidence of 
thrombotic complications in critically ill ICU patients with COVID-19: An updated analysis. Thrombosis Research 2020.

141. Zhang L, Yan X, Fan Q, Liu H, Liu X, Liu Z, Zhang Z: D-dimer levels on admission to predict in-hospital mortality in patients with Covid-19. Journal of Thrombosis and Haemostasis 2020.

142. Ayoade F, Cotelingam J, Joel Chandranesan AS: Disseminated Mycobacterium aviumIntracellulare Complex Infection Presenting With Disseminated Intravascular Coagulation in an AIDS Patient. J Investig Med High Impact Case Rep 2017, 5(4):2324709617740904-2324709617740904.

143. Tabata MM BAaSN: Disseminated Mycobacterium Avium Complex Mimicking MultiOrgan Sarcoidosis in a Patient with Systemic Lupus Erythematosus Treated with Rituximab. Advancements in Case Studies 2019, 2(2).

144. Ishikawa G, Acquah SO, Salvatore M, Padilla ML: Elevated serum D-dimer level is associated with an increased risk of acute exacerbation in interstitial lung disease. Respiratory Medicine 2017, 128:78-84.

145. Alhassan SAA: Estimation and Assessment of D-Dimer Levels in Sudanese Patients with Pulmonary Tuberculosis. Open Access Library Journal 2017, 4(02):1.

146. Garren B, Caboot J: MYCOBACTERIUM AVIUM COMPLEX MEDIASTINAL LYMPHADENITIS IN AN IMMUNOCOMPETENT ADOLESCENT WITH EROSION INTO THE AIRWAY. Chest 2018, 154(4):814A.

147. Shen Y, Yang T, Jia L, Wang T, Chen L, Wan C, Wang L, Yan Y, Yi Q: A potential role for D-dimer in the diagnosis of tuberculous pleural effusion. Age 2013, 52:15.

148. Parker AE, Bermudez LE: Sequence and characterization of the glyceraldehyde-3phosphate dehydrogenase of Mycobacterium avium: correlation with an epidermal growth factor binding protein. Microbial pathogenesis 2000, 28(3):135-144.

149. De Moerloose P, Casini A, Neerman-Arbez M: Congenital fibrinogen disorders: an update. In: Seminars in thrombosis and hemostasis: 2013. Thieme Medical Publishers: 585-595.

150. Jiang Y, Doolittle RF: The evolution of vertebrate blood coagulation as viewed from a comparison of puffer fish and sea squirt genomes. Proceedings of the National Academy of Sciences 2003, 100(13):7527-7532.

151. Royle N, Irwin D, Koschinsky M, MacGillivray R, Hamerton J: Human genes encoding prothrombin and ceruloplasmin map to 11p11-q12 and 3q21-24, respectively. Somatic cell and molecular genetics 1987, 13(3):285-292.

152. Henrickson SE: Learning from our immunological history: What can SARS-CoV teach us about SARS-CoV-2? Science Immunology 2020, 5(46).

153. Cascella M, Rajnik M, Cuomo A, Dulebohn SC, Di Napoli R: Features, evaluation and treatment coronavirus (COVID-19). In: StatPearls [Internet]. StatPearls Publishing; 2020.

154. Enache-Angoulvant A, Hennequin C: Invasive Saccharomyces Infection: A Comprehensive Review. Clinical Infectious Diseases 2005, 41(11):1559-1568.

155. Pérez-Torrado R, Querol A: Opportunistic strains of Saccharomyces cerevisiae: a potential risk sold in food products. Frontiers in microbiology 2016, 6:1522.

156. Tawfik OW, Papasian CJ, Dixon AY, Potter LM: Saccharomyces cerevisiae pneumonia in a patient with acquired immune deficiency syndrome. Journal of clinical microbiology 1989, 27(7):1689-1691. 
157. Dhillon MS, Bowling M: Saccharomyces Cerevisiae Empyema. In: D48 LUNG INFECTION CASE REPORTS I: FUNGAL INFECTIONS. 2016: A7150-A7150.

158. Greer $\mathrm{AE}$, Gemoets $\mathrm{HN}$ : The coexistence of pathogenic fungi in certain chronic pulmonary diseases: with especial reference to pulmonary tuberculosis (a preliminary report). Diseases of the Chest 1943, 9(3).

159. Akram SM, Attia FN: Mycobacterium avium intracellulare. In: StatPearls [Internet]. StatPearls Publishing; 2019.

160. Griffith DE, Aksamit TR: Mycobacterium avium Complex and Bronchiectasis. There's Something Happening Here. In.: American Thoracic Society; 2018.

161. Auwaerter PMD: Coronavirus COVID-19 (SARS-CoV-2). In.: The Johns Hopkins University; 2020.

162. Sulik-Tyszka B, Snarski E, Niedźwiedzka M, Augustyniak M, Myhre TN, Kacprzyk A, Swoboda-Kopeć E, Roszkowska M, Dwilewicz-Trojaczek J, Jędrzejczak WW: Experience with Saccharomyces boulardii probiotic in oncohaematological patients. Probiotics and antimicrobial proteins 2018, 10(2):350-355.

163. Algazaq JN, Akrami K, Martinez F, McCutchan A, Bharti AR: Saccharomyces cerevisiae laryngitis and oral lesions in a patient with laryngeal carcinoma. Case reports in infectious diseases 2017, 2017.

164. Griffith DE: Overview of nontuberculous mycobacterial infections in HIV-negative patients. Accessed April 2014, 29.

165. Currier JS: Mycobacterium avium complex (MAC) infections in HIV-infected patients. UpToDate Waltham, MA: UpToDate Inc(Accessed on February 27, 2018) 2003.

166. Daley CL: Mycobacterium avium complex disease. Tuberculosis and Nontuberculous Mycobacterial Infections 2017:663-701.

167. Chertow GM, Marcantonio ER, Wells RG: Saccharomyces cerevisiae empyema in a patient with esophago-pleural fistula complicating variceal sclerotherapy. Chest 1991, 99(6):1518-1519.

168. Mydlik M, Tkacova E, Szovenyiova K, Mizla P, Derzsiova K: Saccharomyces cerevisiae peritonitis complicating CAPD. Peritoneal Dialysis International 1996, 16(2):188-188.

169. Posteraro B, Sanguinetti M, D’Amore G, Masucci L, Morace G, Fadda G: Molecular and epidemiological characterization of vaginal Saccharomyces cerevisiae isolates. Journal of clinical microbiology 1999, 37(7):2230-2235.

170. Senneville E, Ajana F, Gérard Y, Bourez J-M, Alfandari S, Chidiac C, Mouton Y: Bilateral ureteral obstruction due to Saccharomyces cerevisiae fungus balls. Clinical infectious diseases 1996, 23(3):636-637.

171. Almanza L, Debien B, Fontaine B, Brinquin L: Four hours for a record, or a severe fuminating cellulitis: can Saccharomyces cerevisiae be the causal agent? In: Annales francaises d'anesthesie et de reanimation: 1998. 130-132.

172. Koirala J: Mycobacterium avium-intracellulare. Medscape reference 2012.

173. Huang C, Wang Y, Li X, Ren L, Zhao J, Hu Y, Zhang L, Fan G, Xu J, Gu X et al: Clinical features of patients infected with 2019 novel coronavirus in Wuhan, China. Lancet 2020, 395(10223):497-506.

174. Hopkins C, Surda P, Hopkins C, Kumar N: Presentation of new onset anosmia during the COVID-19 pandemic. Rhinology 2020.

175. Chen D, Xu W, Lei Z, Huang Z, Liu J, Gao Z, Peng L: Recurrence of positive SARSCoV-2 RNA in COVID-19: A case report. Int J Infect Dis 2020, 93:297-299. 
176. Muehrcke DD, Lytle BW, Cosgrove III DM: Surgical and long-term antifungal therapy for fungal prosthetic valve endocarditis. The Annals of thoracic surgery 1995, 60(3):538-543.

177. Ubeda P, Viudes A, Perez BC, Marques JL, Peman J, Gobernado M: Endocarditis caused by Saccharomyces cerevisiae on the prosthetic valve. Enferm Infecc Microbiol Clin 2000, 18(3): 142.

178. Smith D, Metzgar D, Wills C, Fierer J: Fatal Saccharomyces cerevisiae aortic graft infection. J Clin Microbiol 2002, 40(7):2691-2692.

179. Koirala J: Mycobacterium Avium Complex (MAC) (Mycobacterium AviumIntracellulare [MAI]). In.: Medscape; 2019.

180. Tichenor WS, Thurlow J, McNulty S, Brown-Elliott BA, Wallace Jr RJ, Falkinham III JO: Nontuberculous mycobacteria in household plumbing as possible cause of chronic rhinosinusitis. Emerging infectious diseases 2012, 18(10):1612.

181. Jin Y, Yang H, Ji W, Wu W, Chen S, Zhang W, Duan G: Virology, epidemiology, pathogenesis, and control of COVID-19. Viruses 2020, 12(4):372.

182. Lherm T, Monet C, Nougière B, Soulier M, Larbi D, Le Gall C, Caen D, Malbrunot C: Seven cases of fungemia with Saccharomyces boulardii in critically ill patients. Intensive care medicine 2002, 28(6):797-801.

183. Cassone M, Serra P, Mondello F, Girolamo A, Scafetti S, Pistella E, Venditti M: Outbreak of Saccharomyces cerevisiae subtype boulardii fungemia in patients neighboring those treated with a probiotic preparation of the organism. Journal of clinical microbiology 2003, 41(11):5340-5343.

184. Von Reyn CF, Marlow J, Arbeit R, Barber T, Falkinham J: Persistent colonisation of potable water as a source of Mycobacterium avium infection in AIDS. The Lancet 1994, 343(8906): 1137-1141.

185. Organization WH: Coronavirus disease 2019 (COVID-19): situation report, 74. 2020.

186. Taylor G, Buchanan-Chell M, Kirkland T, McKenzie M: Trends and sources of nosocomial fungaemia: Trends und Ursprünge nosokomialer Fungämien. Mycoses 1994, 37(5-6):187-190.

187. Shi H, Han X, Jiang N, Cao Y, Alwalid O, Gu J, Fan Y, Zheng C: Radiological findings from 81 patients with COVID-19 pneumonia in Wuhan, China: a descriptive study. The Lancet Infectious Diseases 2020.

188. Verity R, Okell LC, Dorigatti I, Winskill P, Whittaker C, Imai N, Cuomo-Dannenburg G, Thompson H, Walker PG, Fu H: Estimates of the severity of coronavirus disease 2019: a model-based analysis. The Lancet Infectious Diseases 2020.

189. Coronavirus Disease 2019 (COVID-19) [https://www.cdc.gov/coronavirus/2019ncov/need-extra-precautions/people-at-higher-risk.html]

190. Anaissie E, Bodey GP, Kantarjian H, Ro J, Vartivarian SE, Hopfer R, Hoy J, Rolston K: New spectrum of fungal infections in patients with cancer. Reviews of infectious diseases 1989, 11(3):369-378.

191. Candelli M, Nista EC, Nestola M, Armuzzi A, Silveri NG, Gasbarrini G, Gasbarrini A: Saccharomyces cerevisiae-associated diarrhea in an immunocompetent patient with ulcerative colitis. Journal of clinical gastroenterology 2003, 36(1):39-40.

192. Cairoli R, Marenco P, Perego R, De Cataldo F: Saccharomyces cerevisiae fungemia with granulomas in the bone marrow in a patient undergoing BMT. Bone marrow transplantation 1995, 15(5):785. 
193. Riquelme AJ, Calvo MA, Guzmán AM, Depix MS, García P, Pérez C, Arrese M, Labarca JA: Saccharomyces cerevisiae fungemia after Saccharomyces boulardii treatment in immunocompromised patients. Journal of clinical gastroenterology 2003, 36(1):41-43.

194. Viggiano M, Badetti C, Bernini V, Garabedian M, Manelli J: Saccharomyces boulardii fungemia in a patient with severe burns. In: Annales francaises d'anesthesie et de reanimation: 1995. 356-358.

195. Ruiz-Esquide F, Diaz M, Wu E, Silva V: Verrucous endocarditis secondary to Saccharomyces cerevisiae. A case report. Revista medica de Chile 2002, 130(10):11651169.

196. Sexton P, Harrison A: Susceptibility to nontuberculous mycobacterial lung disease. European Respiratory Journal 2008, 31(6):1322-1333.

197. Roy S, Dickerson R, Khanna S, Collard E, Gnyawali U, Gordillo GM, Sen CK: Particulate $\beta$-glucan induces TNF- $\alpha$ production in wound macrophages via a redox-sensitive NFк及-dependent pathway. Wound Repair and Regeneration 2011, 19(3):411-419.

198. Yang Z, Marshall JS: Zymosan treatment of mouse mast cells enhances dectin-1 expression and induces dectin-1-dependent reactive oxygen species (ROS) generation. Immunobiology 2009, 214(4):321-330.

199. Karumuthil-Melethil S, Gudi R, Johnson BM, Perez N, Vasu C: Fungal ß-glucan, a Dectin-1 ligand, promotes protection from type 1 diabetes by inducing regulatory innate immune response. The Journal of Immunology 2014, 193(7):3308-3321.

200. Goyal S, Castrillón-Betancur JC, Klaile E, Slevogt H: The interaction of human pathogenic fungi with C-type lectin receptors. Frontiers in Immunology 2018, 9:1261.

201. Allen MJ, Voelker DR, Mason RJ: Interactions of surfactant proteins A and D with Saccharomyces cerevisiae and Aspergillus fumigatus. Infection and immunity 2001, 69(4):2037-2044.

202. Takahara K, Arita T, Tokieda S, Shibata N, Okawa Y, Tateno H, Hirabayashi J, Inaba K: Difference in Fine Specificity to Polysaccharides of \& Candida albicans\& Mannoprotein between Mouse SIGNR1 and Human DC-SIGN. Infection and Immunity 2012, 80(5):1699.

203. de Jong MA, Vriend LE, Theelen B, Taylor ME, Fluitsma D, Boekhout T, Geijtenbeek TB: $\mathrm{C}$-type lectin Langerin is a $\beta$-glucan receptor on human Langerhans cells that recognizes opportunistic and pathogenic fungi. Molecular immunology 2010, 47(6):1216-1225.

204. Lefrancois LH, Bodier CC, Cochard T, Canepa S, Raze D, Lanotte P, Sevilla IA, Stevenson $\mathrm{K}$, Behr MA, Locht $\mathrm{C}$ : Novel feature of Mycobacterium avium subsp. paratuberculosis, highlighted by characterization of the heparin-binding hemagglutinin adhesin. Journal of bacteriology 2013, 195(21):4844-4853.

205. Maeda N, Nigou J, Herrmann J-L, Jackson M, Amara A, Lagrange PH, Puzo G, Gicquel B, Neyrolles O: The Cell Surface Receptor DC-SIGN Discriminates betweenMycobacterium Species through Selective Recognition of the Mannose Caps on Lipoarabinomannan. Journal of Biological Chemistry 2003, 278(8):5513-5516.

206. Schorey JS, Holsti MA, Ratliff TL, Allen PM, Brown EJ: Characterization of the fibronectin-attachment protein of Mycobacterium avium reveals a fibronectinbinding motif conserved among mycobacteria. Molecular microbiology 1996, 21(2):321-329. 
207. Zu Bentrup KH, Miczak A, Swenson DL, Russell DG: Characterization of Activity and Expression of Isocitrate Lyase in Mycobacterium avium andMycobacterium tuberculosis. Journal of bacteriology 1999, 181(23):7161-7167.

208. Ohara N, Ohara-Wada N, Kitaura H, Nishiyama T, Matsumoto S, Yamada T: Analysis of the genes encoding the antigen 85 complex and MPT51 from Mycobacterium avium. Infection and immunity 1997, 65(9):3680-3685.

209. Huntley JF, Stabel JR, Bannantine JP: Immunoreactivity of the Mycobacterium avium subsp. paratuberculosis 19-kDa lipoprotein. BMC microbiology 2005, 5(1):3.

210. Viale MN, Echeverria-Valencia G, Romasanta P, Mon ML, Fernandez M, Malchiodi E, Romano MI, Gioffré AK, Santangelo MdlP: Description of a novel adhesin of Mycobacterium avium subsp. paratuberculosis. BioMed research international 2014, 2014.

211. Wang Y, Dong C, Hu Y, Li C, Ren Q, Zhang X, Shi H, Zhou M: Temporal Changes of CT Findings in 90 Patients with COVID-19 Pneumonia: A Longitudinal Study. Radiology 2020:200843.

212. Pan Y, Zhang D, Yang P, Poon LL, Wang Q: Viral load of SARS-CoV-2 in clinical samples. The Lancet infectious diseases 2020, 20(4):411-412.

213. Liu T, Zhang J, Yang Y, Zhang L, Ma H, Li Z, Zhang J, Cheng J, Zhang X, Wu G: The potential role of $\mathbf{I L - 6}$ in monitoring coronavirus disease 2019. Available at SSRN 35487612020.

214. Yoshikawa T, Hill T, Li K, Peters CJ, Tseng C-TK: Severe Acute Respiratory Syndrome (SARS) Coronavirus-Induced Lung Epithelial Cytokines Exacerbate SARS Pathogenesis by Modulating Intrinsic Functions of Monocyte-Derived Macrophages and Dendritic Cells. Journal of Virology 2009, 83(7):3039.

215. Pedersen SF, Ho Y-C: SARS-CoV-2: a storm is raging. The Journal of clinical investigation 2020, 130(5).

216. Li Z, Yi Y, Luo X, Xiong N, Liu Y, Li S, Sun R, Wang Y, Hu B, Chen W: Development and clinical application of a rapid IgM-IgG combined antibody test for SARS-CoV-2 infection diagnosis. Journal of medical virology 2020.

217. Al Janabi MG, Dhillon MS, Bowling M: Saccharomyces Cerevisiae Empyema. In: D48 LUNG INFECTION CASE REPORTS I: FUNGAL INFECTIONS. American Thoracic Society; 2016: A7150-A7150.

218. Teblick A, Jansens H, Dams K, Somville FJ, Jorens PG: Boerhaave's syndrome complicated by a Saccharomyces cerevisiae pleural empyema. Case report and review of the literature. Acta Clinica Belgica 2018, 73(5):377-381.

219. Fadhel M, Patel S, Liu E, Levitt M, Asif A: Saccharomyces cerevisiae fungemia in a critically ill patient with acute cholangitis and long term probiotic use. Medical mycology case reports 2018, 23:23-25.

220. Stier H, Ebbeskotte V, Gruenwald J: Immune-modulatory effects of dietary Yeast Beta1, 3/1, 6-D-glucan. Nutrition journal 2014, 13(1):38.

221. Buckland MS, Mylonaki M, Rampton D, Longhurst HJ: Serological markers (antiSaccharomyces cerevisiae mannan antibodies and antineutrophil cytoplasmic antibodies) in inflammatory bowel disease: diagnostic utility and phenotypic correlation. Clin Diagn Lab Immunol 2005, 12(11):1328-1330. 
222. Hartman TE, Jensen E, Tazelaar HD, Hanak V, Ryu JH: CT findings of granulomatous pneumonitis secondary to Mycobacterium avium-intracellulare inhalation:"hot tub lung”. American Journal of Roentgenology 2007, 188(4):1050-1053.

223. Kasperbauer SH, Daley CL: Diagnosis and treatment of infections due to Mycobacterium avium complex. In: Seminars in respiratory and critical care medicine: 2008. () Thieme Medical Publishers: 569-576.

224. Koirala J: What testing is included in the workup of suspected mycobacterium avium complex (MAC) (mycobacterium avium-intracellulare [MAI]) infection? In.: Medscape; 2019.

225. Pettipher CA, Karstaedt AS, Hopley M: Prevalence and clinical manifestations of disseminated Mycobacterium avium complex infection in South Africans with acquired immunodeficiency syndrome. Clinical infectious diseases 2001, 33(12):20682071.

226. Gordon CJ, Tchesnokov EP, Feng JY, Porter DP, Götte M: The antiviral compound remdesivir potently inhibits RNA-dependent RNA polymerase from Middle East respiratory syndrome coronavirus. Journal of Biological Chemistry 2020, 295(15):4773-4779.

227. Cai Q, Yang M, Liu D, Chen J, Shu D, Xia J, Liao X, Gu Y, Cai Q, Yang Y et al: Experimental Treatment with Favipiravir for COVID-19: An Open-Label Control Study. Engineering 2020.

228. Kontoyiannis DP: Fluconazole inhibits pseudohyphal growth in Saccharomyces cerevisiae. Chemotherapy 2000, 46(2):100-103.

229. Adelman MH, Addrizzo-Harris DJ: Management of nontuberculous mycobacterial pulmonary disease. Current opinion in pulmonary medicine 2018, 24(3):212-219. 